Encontro Nacional de

Economia Industrial e Inovação
Indústria e Desenvolvimento Econômico:

desafios e perspectivas

18 a 20 de setembro de 2018

Uberlândia - Minas Gerais

\title{
Saneamento Básico nas Mesorregiões de Minas Gerais: Desafios para a Produtividade Industrial
}

\author{
Regiane Lopes Rodrigues \\ FUCAMP \\ rlregianelopes@gmail.com
}

\author{
Welber Tomás de Oliveira \\ IERI/UFU \\ weelber@live.com
}

\author{
Carlos C. S. Saiani \\ IERI/UFU \\ ssaiani@ufu.br
}

\section{Resumo}

As atividades industriais são fortemente impactadas por problemas no saneamento. Devido à água ser um importante insumo de produção para diversos setores industriais, quantidades insuficientes de água para a produção afetam negativamente a produtividade total dos fatores das empresas industriais. Além disso, quantidades insuficientes de água para o consumo humano, água contaminada e problemas associados aos outros serviços de saneamento básico prejudicam, por meio do canal da saúde, a produtividade dos trabalhadores. Apesar do Brasil ter relativa abundância de recursos hídricos, os baixos investimentos históricos em infraestrutura resultaram em indisponibilidade hídrica e/ou racionamentos em vários locais; déficits de acesso; perdas na distribuição e problemas de qualidade da água ofertada. Nesse contexto, o objetivo deste estudo foi analisar os déficits de acesso a saneamento básico nas mesorregiões mineiras, avaliando desigualdades, evoluções e convergências entre 1991 e 2010. Ademais, foram realizadas simulações para verificar a possibilidade do cumprimento das metas dos Objetivos de Desenvolvimento Sustentável (ODSs) de universalização equitativa do acesso a abastecimento de água e coleta de esgoto. As evidências obtidas sinalizaram: i) disparidades entre as mesorregiões; ii) reduções mais acentuadas dos déficits nos anos 1990; iii) tendência de convergência dos acessos entre as mesorregiões e os "mais pobres" e os "mais ricos"; e iv) não cumprimento das metas dos ODSs.

Palavras-chave: Saneamento Básico. Desigualdade. Indústria.

\begin{abstract}
Industrial activities are heavily impacted by sanitation problems. Due to water being an important input of production for several industrial sectors, insufficient quantities of water for production negatively affect the total factor productivity of industrial enterprises. In addition, insufficient quantities of water for human consumption, contaminated water and problems associated with other basic sanitation services harm, throug health channel, the productivity of workers. Although Brazil has a relative abundance of water resources, the low investments in the last decades in infrastructure have resulted in water unavailability and / or rationing in several places, access deficits; distribution losses and water quality problems. So this article aims to investigate the deficits of access to basic sanitation in the regions of Minas Gerais, assessing inequalities, evolutions and convergences between 1991 and 2010. In addition, simulations were carried out to verify the possibility of achieving the targets of the Sustainable Development Goals (SDGs) of equitable access to water supply and sewage collection. The evidences obtained indicated: i) disparities between regions of Minas Gerais; (ii) sharper reductions in deficits in the 1990s; iii) trend of convergence between the regions and the "poorest" and the "richest"; and iv) non-compliance with SDG targets.
\end{abstract}

Keywords: Basic Sanitation. Inequality. Industry.

Classificação JEL: L90. L95. Q25.

Área ABEIN: Área 4 - Redes e sistemas urbanos, regionais e nacionais;

4.2 Economias Regionais e Urbanas. 


\section{Introdução}

O saneamento básico corresponde ao conjunto de serviços e infraestruturas de abastecimento de água (captação, tratamento e distribuição); esgotamento sanitário (coleta, transporte, tratamento e disposição final); limpeza urbana e manejo dos resíduos sólidos (coleta, transporte, transbordo, tratamento e destinação final); e drenagem e manejo das águas pluviais urbanas (BRASIL, 2007). Situações inadequadas nestes serviços, tanto em termos de acesso como de qualidade, impactam negativamente o meio ambiente, a saúde e a geração de produto e renda. Ou seja, afetam dimensões dos três pilares do desenvolvimento sustentável - ambiental, social e econômico (ROMEIRO, 2003).

As atividades industriais são fortemente impactadas por problemas no saneamento. Diretamente, devido à água ser um importante insumo de produção para os mais diversos setores industriais (ANA, 2017). Assim, água em quantidades insuficientes para a produção afetam negativamente a produtividade total dos fatores (PTF) das empresas industriais (MOYO, 2011). Indiretamente, quantidades insuficientes de água para o consumo humano, água contaminada e problemas associados aos outros serviços de saneamento básico, principalmente ao esgotamento sanitário prejudicam, por meio do canal da saúde, a produtividade dos trabalhadores (CVJETANOVIC, 1986; HELLER, 1997; PNUD, 2006).

No trabalho seminal de Aschauer (1990), é constatado que gastos públicos com utilidades públicas, como o abastecimento de água, estimularam ganhos de produtividade e o crescimento nos Estados Unidos. Evidências nesse sentido também são apresentadas por: Uchimura e Gao (1993), Bregman e Marom (1999), Mastromarco e Woitek (2006), Rigolon (1998), Mussolini e Teles (2010) e Schettini e Azzoni (2015).

Apesar destes potenciais efeitos positivos e do Brasil ter relativa abundância de recursos hídricos, o abastecimento de água para consumo e produção é um importante desafio. Historicamente, investimentos em infraestruturas de captação, distribuição e tratamento de água foram aquém dos necessários, devido a uma aparente desmotivação política, à persistência de restrições e à ineficiência da maioria dos provedores (TUROLLA, 2002; TONETO JÚNIOR; SAIANI, 2006). Os resultados dos baixos investimentos são: i) indisponibilidade hídrica e/ou racionamentos em vários locais; ii) déficits de acesso; iii) perdas na distribuição; e iv) problemas de qualidade da água ofertada (ANA, 2010; IBGE, 2011; SAIANI et al., 2015).

Assim, a universalização do saneamento no Brasil ainda está longe de ser atingida. Os déficits de acesso são mais significativos no esgotamento sanitário. Segundo o último Censo Demográfico de 2010, do Instituto Brasileiro de Geografia e Estatística (IBGE), aproximadamente 17\% dos domicílios não são conectados a redes gerais de abastecimento de água e proporção bastante superior, $45 \%$, não são ligados a redes de esgoto. Tais déficits distribuem-se de forma desigual, sendo mais concentrados nos mais pobres, em áreas periféricas ou rurais e em regiões menos desenvolvidas, refletindo as desigualdades regionais presentes no país (BARAT, 1998; MOTTA, 2004; REZENDE et al., 2007). Apesar de só existirem dados para avaliar o problema de acesso a saneamento em todo território brasileiro para domicílios e pessoas, é plausível supor que localidades em que os déficits são maiores, também é maior a probabilidade de que as empresas sejam prejudicadas, tanto diretamente, por problemas no fornecimento da água para a produção, como indiretamente, pelos efeitos de inadequações do saneamento sobre a produtividade dos trabalhadores.

Deve-se ressaltar, ainda, que estes problemas nos serviços de saneamento, assim como gargalos em outras infraestruturas econômicas (IPEA, 2010), sejam alguns dos determinantes da baixa produtividade das empresas industriais brasileiras. Os trabalhos organizados no livro de De Negri e Cavalcante (2014) estimam a produtividade do trabalho e a PTF no Brasil nas últimas décadas, não deixando dúvidas que, independentemente da medida e do método, a produtividade é baixa e cresce aquém do necessário.

O estado de Minas Gerais reflete, em uma escala reduzida, as desigualdades entre as grandes regiões brasileiras. Neste estado, há mesorregiões mais dinâmicas, com melhores condições socioeconômicas e mesorregiões bem menos desenvolvidas, em especial aquelas situadas mais ao norte do estado, próximas à região Nordeste brasileira. Ademais, em várias mesorregiões grande parte dos trabalhadores industriais é de atividades que demandam relativamente mais água como insumo de produção, o que potencializa os possíveis efeitos discutidos de inadequações do saneamento sobre a produtividade (do trabalho e PTF) As desigualdades em diferentes dimensões - renda, atividades econômicas, emprego e condições de saúde e de educação - entre localidades mineiras, inclusive entre mesorregiões, são exploradas em diversos trabalhos anteriores: Queiroz (2003), Salvato et al. (2006), Simão (2006), Soares (2009) e Costa et al. 
(2012), entre outros. Contudo, não foi encontrado um trabalho que comparou, de forma abrangente, as mesorregiões mineiras em termos de acesso a saneamento (abastecimento de água e coleta de esgoto).

Este estudo pretende contribuir para esta lacuna da literatura empírica. Tomando como motivações as desigualdades de acesso a saneamento no território brasileiro, as desigualdades em diversas dimensões das mesorregiões mineiras e os efeitos potenciais do saneamento, o objetivo é analisar a situação, em 2010, dos déficits de acesso a abastecimento de água e a coleta de esgoto nas mesorregiões do estado de Minas Gerais, investigando a existência de desigualdades de acesso a serviços de saneamento. Além disso, o estudo avalia as evoluções dos déficits e de suas distribuições nas décadas de 1990 e 2000, averiguando, ainda, a ocorrência de convergências (reduções das desigualdades) entre as mesorregiões e os "mais pobres" e "mais ricos" em cada mesorregião. Para isso, são usados dados dos Censos de 1991, 2000 e 2010.

A comparação das evoluções nas décadas de 1990 e 2000 é interessante por refletirem dois momentos das políticas públicas para o saneamento. Após um período de quase 20 anos de vigência do Plano Nacional de Saneamento (Planasa), as políticas federais na década de 1990 foram mais "pontuais e desarticuladas" e com volumes restritos de recursos federais direcionados ao setor (TUROLLA, 2002). O início da década de 2000 também foi caracterizado pela ausência de uma política nacional, que só voltou a ser discutida em 2007, com a promulgação da Lei n ${ }^{\circ} 11.445$, a Lei do Saneamento Básico (BRASIL, 2007), e com a alocação de mais recursos federais pelo Programa de Aceleração do Crescimento (PAC). A Lei definiu, ainda, parâmetros de provisão que os provedores devem seguir, o que pode influenciar as evoluções dos acessos.

Nos anos 2000, também se destaca o provável incentivo dos Objetivos do Desenvolvimento do Milênio (ODMs), acordo internacional firmado, em 2000, em conferência da Organização das Nações Unidas (ONU). Os 8 ODMs eram considerados os principais desafios para o novo milênio que se iniciava. No geral, foram estabelecidas metas que deveriam ser atingidas até 2015. Em relação ao saneamento, foram definidas metas de reduções dos déficits de acesso considerando como referências as situações em 1990.

Encerrado o prazo dos ODMs, ainda em 2015, um novo acordo internacional foi firmado no âmbito da ONU, sendo definidos 17 Objetivos de Desenvolvimento Sustentável (ODSs) e 169 metas. Nos ODSs, a importância dos serviços de saneamento para o alcance do desenvolvimento sustentável é reconhecida diretamente no "Objetivo 6" - "assegurar a disponibilidade e gestão sustentável da água e saneamento para todos" (ONU, 2015) -, para o qual são definidas algumas metas para o setor, como metas de universalização do acesso a abastecimento de água e coleta de esgoto, de forma equitativa, até 2030 (metas 6.1 e 6.2). Ademais, pode-se ilustrar a interface com a produção e produtividade da indústria por meio das metas: i) 8.2 - "atingir níveis mais elevados de produtividade das economias"); e ii) 9.1 - "desenvolver infraestrutura de qualidade, confiável, sustentável e resiliente para apoiar o desenvolvimento econômico e o bem-estar".

Diante de tal fato, adicionalmente, o estudo avaliar se as metas de universalização do acesso, até 2030, a abastecimento de água e a coleta de esgoto podem ser atingidas em Minas Gerais equitativamente - em todas as mesorregiões e nos domicílios "mais pobres" e "mais ricos" - se forem mantidas as evoluções das décadas de 1990 e 2000. Para isso, são simuladas as evoluções dos déficits até 2030 pelas taxas de variações anuais observadas: i) na década de 1990; ii) na década de 2000; e iii) nas duas décadas conjuntas.

O Programa Conjunto de Monitoramento do Abastecimento de Água, de Saneamento e Higiene da Organização Mundial da Saúde (OMS) e da Unicef, ficou responsável pelo acompanhamento mundial das metas de universalização do acesso a saneamento. Em relatório de 2017, a entidade ressaltou os avanços nacionais, porém deu ênfase aos déficits ainda existentes, em especial aos associados à renda e à localização, apontando como objetivo "não deixar ninguém para trás" no avanço da cobertura dos serviços (JMP, 2017).

Antecipadamente, as evidências deste estudo sinalizam que todas as mesorregiões eram deficitárias, em 2010, nos dois serviços. Porém, há disparidades entre elas: os déficits de acesso eram maiores na coleta de esgoto e nas mesorregiões com menores taxas de urbanização e menores níveis de renda. As evidências também sugerem: i) reduções dos déficits mais acentuadas nos anos 1990; ii) domicílios "mais pobres" com menores coberturas nos dois serviços em todas as mesorregiões; iii) tendência de convergências no tempo entre os acessos das mesorregiões e dos "mais pobres" e "mais ricos"; iv) todas as mesorregiões não atingirão as metas dos ODSs de universalização dos acessos se mantiverem as mesmas evoluções dos anos 1990 e 2000; v) as diferenças de acesso entre "mais pobres" e "mais ricos" reduziram de 1991 a 2010, de modo que, mesmo que ainda em situações piores, não é possível afirmar que os "mais pobres" estão 
"ficando para trás" na expansão das coberturas dos serviços Minas Gerais; mas, vi) algumas mesorregiões, em especial as mais ao norte do estado, persistem atrás das mais desenvolvidas em termos de acesso.

O estudo é composto por duas seções, além dessa introdução e das considerações finais. Na primeira, os déficits de acesso ao abastecimento de água e a coleta de esgoto nas mesorregiões de Minas Gerais são caracterizados. Ademais, são analisadas suas evoluções distribuições nas décadas de 1990 e 2000, avaliando se ocorreram convergências de acessos entre as mesorregiões e "mais pobres" e "mais ricos". Na segunda, é discutida a importância do saneamento para os ODSs e são feitas simulações para avaliar se as metas de universalização seriam atingidas, igualitariamente, se forem mantidas as evoluções dos anos 1990 e 2000.

\section{Déficits de acesso nas mesorregiões mineiras: desigualdades, evoluções e convergências}

A seguir, são utsados dados dos Censos de 1991, 2000 e 2010 do IBGE para: i) caracterizar a situação, em 2010, dos déficits de acesso a abastecimento de água e a coleta de esgoto nas mesorregiões de Minas Gerais; ii) avaliar as evoluções dos déficits aos dois serviços nestas mesorregiões nas décadas de 1990 e 2000; e iii) avaliar se ocorreu, entre as mesorregiões, convergência do acesso (reduções das desigualdades).

Inicialmente, é importante ilustrar aspectos que fundamentam as análises. O primeiro refere-se aos déficits de acesso a serviços de saneamento no Brasil apresentarem tendência de queda no tempo, mas em ritmo bem aquém do necessário para a universalização em um curto prazo, principalmente no caso da coleta de esgoto. Ademais, os déficits distribuem-se de forma desigual pelo país, observando-se: i) desequilíbrio entre os domicílios conectados à rede de abastecimento de água e à rede coletora de esgoto; ii) menores coberturas em áreas rurais; iii) concentração do acesso nos grandes centros, em detrimento de periferias e dos municípios do interior; iv) população mais pobre com menor probabilidade de acesso; e v) coberturas distintas nas grandes regiões geográficas brasileiras - conforme pode ser observado na Tabela 1 (BNDES, 1998; BARAT, 1998; MOTTA, 2004; REZENDE et al., 2007; SAIANI; TONETO JÚNIOR, 2010).

Tabela 1 - Brasil: déficits de acesso a saneamento básico, segundo os serviços e as macrorregiões (2010)

\begin{tabular}{c|c|c}
\hline Regiões & Abastecimento de Água & Coleta de Esgoto \\
\hline Norte & 46,2 & 86,1 \\
Nordeste & 23,9 & 66,0 \\
Sudeste & 9,8 & 19,0 \\
Sul & 14,6 & 54,3 \\
Centro-Oeste & 18,6 & 61,7 \\
\hline Brasil & $\mathbf{1 7 , 4}$ & $\mathbf{4 4 , 6}$ \\
\hline
\end{tabular}

Fonte: IBGE, Censo Demográfico de 2010. Elaboração própria.

Para o cálculo dos déficits da Tabela 1 - e de todos os demais analisados neste estudo -, é considerada a proporção de domicílios sem acesso ao serviço em dada localidade pela forma apontada pela literatura e estabelecida pela Lei $\mathrm{n}^{\circ} 11.445$ (Lei do Saneamento Básico) como a mais adequada para os dois serviços: rede geral. Esta é defendida devido à regularidade do serviço, ao menor risco de contaminação de recursos hídricos e solos, que geram impactos negativos no meio ambiente e na saúde. Ademais, para avaliações de políticas para o setor, a rede geral deve ser considerada por ser mais associada a decisões de provedores, pois o acesso depende da adesão dos usuários - demanda -, mas é necessária a oferta. Formas alternativas, como poços e fossas sépticas, dependem de ações individuais (BRASIL, 2007; REZENDE et al., 2007).

Os déficits de acesso diferem significativamente entre os serviços - muito superiores na coleta de esgoto - e entre as regiões geográficas. Enquanto os déficits de acesso a abastecimento de água e a coleta de esgoto na região Sudeste, em 2010, eram de 9,8\% e 19,0\%, respectivamente; no Norte, eram de 46,2\% e $86,1 \%$; já no Nordeste, eram de $23,9 \%$ e $66,0 \%$. As diferenças inter-regionais do acesso a saneamento podem ser explicadas por diferenças regionais em termos de atributos socioeconômicos que influenciam, pela demanda, a disposição dos consumidores a pagarem pelos serviços (gastos com a conexão e tarifas) e a capacidade de exercer controle social sobre provedores, que, pela oferta, consideram custos e retornos, assim como capacidades de arrecadar e investir. Entre as principais variáveis apontadas como determinantes do acesso estão: população, taxa de urbanização e rendas dos locais e usuários (MOTTA, 2004; TONETO JÚNIOR; SAIANI, 2006; REZENDE et al., 2007; SAIANI et al., 2013a, 2013b, 2015; SNSA, 2011).

$\mathrm{Na}$ introdução, foram apontados trabalhos que discutem diferenças regionais em Minas Gerais em várias dimensões. A Tabela 2 ilustra tal fato, mostrando como as mesorregiões mineiras diferem em termos 
de população, taxa de urbanização, Produto Interno Bruto (PIB) per capita e renda domiciliar per capita. Observa-se a existência de grandes diferenças nas taxas de urbanização - enquanto Metropolitana de Belo Horizonte e Triângulo Mineiro e Alto Paranaíba apresentam taxas acima de 90\%, outras mesorregiões têm taxas abaixo de 70\%, como o Jequitinhonha e o Vale do Mucuri. As diferenças entre as mesorregiões são maiores na população. Por exemplo, os habitantes da Metropolitana de Belo Horizonte representam 32\% da população de Minas Gerais em 2010; já outras mesorregiões têm populações próximas a 2\% do total Central Mineira, Noroeste de Minas e Vale do Mucuri. Diferenças regionais também existem em relação ao nível de renda. A renda domiciliar per capita mensal na Metropolitana de Belo Horizonte era superior a dois salários mínimos de 2010 (R \$ 510), mas em Jequitinhonha era inferior a um salário mínimo. Já no PIB per capita, a Metropolitana de Belo Horizonte e o Triângulo Mineiro e Alto Paranaíba e o Jequitinhonha também apresentavam os maiores e menores valores, respectivamente. Ademais, é possível observar que, nas mesorregiões mineiras, populações, urbanizações e renda tendem a ser correlacionadas positivamente.

Tabela 2 - Minas Gerais: características socioeconômicas, segundo as mesorregiões (2010)

\begin{tabular}{c|c|c|c|c}
\hline Mesorregiões & $\begin{array}{c}\text { População } \\
\text { (habitantes) }\end{array}$ & $\begin{array}{c}\text { Urbanização } \\
(\mathbf{\%})\end{array}$ & $\begin{array}{c}\text { PIB per capita } \\
\text { (R\$ 2010) }\end{array}$ & $\begin{array}{c}\text { Renda domiciliar per } \\
\text { capita } \text { mensal (R\$ 2010) }\end{array}$ \\
\hline Campo das Vertentes & 554.354 & 84,6 & 12.324 & 780 \\
Central Mineira & 412.712 & 87,3 & 13.149 & 714 \\
Jequitinhonha & 699.413 & 62,2 & 5.531 & 428 \\
Metropolitana de Belo Horizonte & 6.236 .117 & 95,3 & 25.737 & 1.163 \\
Noroeste de Minas & 366.418 & 78,2 & 15.558 & 678 \\
Norte de Minas & 1.610 .413 & 69,4 & 8.235 & 500 \\
Oeste de Minas & 955.030 & 88,2 & 13.786 & 801 \\
Sul e Sudoeste de Minas & 2.438 .611 & 81,2 & 16.003 & 811 \\
Triângulo Mineiro e Alto Paranaíba & 2.144 .482 & 91,4 & 23.998 & 954 \\
Vale do Mucuri & 385.413 & 67,7 & 8.231 & 530 \\
Vale do Rio Doce & 1.620 .993 & 80,3 & 13.131 & 643 \\
Zona da Mata & 2.173 .374 & 80,8 & 12.619 & 801 \\
\hline Estado de Minas Gerais & $\mathbf{1 9 . 5 9 7 . 3 3 0}$ & $\mathbf{8 5 , 3}$ & $\mathbf{1 7 . 9 1 7}$ & $\mathbf{8 7 7}$ \\
\hline
\end{tabular}

Fonte: IBGE, Censo Demográfico de 2010. Elaboração própria.

Portanto, os dados da Tabela 2 mostram as discrepâncias das características que podem, baseando-se na literatura, determinar diferenças nos déficits de acesso a abastecimento de água e a coleta de esgoto entre as mesorregiões que compõem o estado de Minas Gerais. Tais diferenças de acesso são analisadas a seguir, na subseção 1.1. Antes disso, a Tabela 3 apresenta a distribuição dos trabalhadores (vínculos formais), em 2016, entre alguns setores selecionados de atividades produtivas que mais demandam água para produção.

Tabela 3 - Minas Gerais: distribuição (\%) dos trabalhadores (vínculos formais), segundo os setores de atividades produtivas com maiores dependências de água para a produção e as mesorregiões (2016)

\begin{tabular}{c|c|c|c|c}
\hline Mesorregiões & $\begin{array}{c}\text { Agropecuária } \\
\text { + Indústria } \\
\text { (\% Total) }\end{array}$ & $\begin{array}{c}\text { Agropecuária } \\
\text { (\% Total) }\end{array}$ & $\begin{array}{c}\text { Indústria } \\
\text { (\% Total) }\end{array}$ & $\begin{array}{c}\text { Atividades Industriais que } \\
\text { mais Demandam Água } \\
\text { (\% da Indústria) }\end{array}$ \\
\hline Campo das Vertentes & 25,1 & 7,6 & 17,5 & 49,2 \\
Central Mineira & 33,3 & 12,3 & 21,0 & 43,1 \\
Jequitinhonha & 18,5 & 10,5 & 8,0 & 18,6 \\
Metropolitana de Belo Horizonte & 16,2 & 1,1 & 15,1 & 29,8 \\
Noroeste de Minas & 37,8 & 22,8 & 15,0 & 71,5 \\
Norte de Minas & 23,5 & 10,3 & 13,2 & 29,9 \\
Oeste de Minas & 40,8 & 6,8 & 34,0 & 24,6 \\
Sul e Sudoeste de Minas & 35,8 & 10,7 & 25,1 & 24,9 \\
Triângulo Mineiro e Alto Paranaíba & 28,5 & 11,1 & 17,4 & 55,5 \\
Vale do Mucuri & 17,5 & 8,7 & 8,8 & 66,1 \\
Vale do Rio Doce & 20,2 & 4,4 & 15,8 & 53,4 \\
Zona da Mata & $\mathbf{2 4 , 7}$ & 4,4 & 20,3 & $\mathbf{2 8 , 9}$ \\
\hline
\end{tabular}

Fonte: Ministério do Trabalho e Emprego, RAIS 2016 e ANA (2017). Elaboração própria.

Agropecuária e indústria são os grandes setores que mais dependem de água para a produção, de modo que são os mais afetados por problemas de falta de água. Em conjunto, estes setores abrangem 25,3\% 
dos trabalhadores do estado, proporção que varia de 17,5\% a 40,8\% entre as mesorregiões. ANA (2017) aponta como as 4 "atividades industriais que mais demandam água para a produção" as indústrias de: produtos alimentícios; derivados do petróleo e biocombustíveis; de papel e celulose; e de metalurgia. Estas seriam as atividades mais suscetíveis a sofrerem os efeitos nocivos de problemas no abastecimento de água diretamente sobre a PTF e indiretamente sobre a produtividade do trabalho. A Tabela 3 também mostra as participações agregadas destas atividades no total de trabalhadores de Minas Gerais e das mesorregiões. No estado, estas atividades abarcam 34,2\% dos trabalhadores, variando nas mesorregiões de 18,6\% a 71,5\%.

\subsection{Caracterização dos déficits de acesso (2010): situações e desigualdades}

A Tabela 4 mostra os déficits de acesso a abastecimento de água e a coleta de esgoto das mesorregiões mineiras em 2010, último ano em que foi realizado Censo pelo IBGE. Observa-se que aproximadamente $14 \%$ dos domicílios não tinham acesso a rede de abastecimento de água e quase $25 \%$ não estavam conectados a redes de esgoto. Tratam-se de déficits superiores aos da região brasileira em que o estado está localizado (Sudeste), mas inferiores aos déficits das demais regiões e do Brasil (Tabela 1). Podem ser destacados outros aspectos sobre o acesso a saneamento nas mesorregiões:

- desequilíbrios inter-regionais: por exemplo, Jequitinhonha com maior déficit de acesso à rede de água -32\%, inferior apenas à região Norte brasileira (Tabela 1) -; e Metropolitana de Belo Horizonte com menor déficit no serviço - igual a 5\%, inferior às médias de todas as regiões brasileiras (Tabela 1); a diferença entre as mesorregiões com o maior e o menor déficit é de quase 26 pontos percentuais;

- no esgoto, a diferença entre o maior déficit e o menor é quase o dobro da diferença na água, sendo o Norte de Minas a mesorregião com o maior déficit de acesso - 67\%, inferior apenas ao da região Norte brasileira (Tabela 1) - e o Triângulo Mineiro e Alto Paranaíba com o menor déficit neste serviço $-12,9 \%$, menor do que os déficits de todas as regiões brasileiras (Tabela 1);

- déficits de acesso, principalmente à coleta de esgoto, da maioria das mesorregiões superiores aos respectivos déficits de Minas Gerais (Tabela 3) e da região Sudeste do país (Tabela 1);

- piores situações das coberturas da coleta de esgoto em todas as mesorregiões mineiras - assim como nas regiões brasileiras -, sendo que, na Metropolitana de Belo Horizonte e no Norte de Minas, os déficits de acesso ao esgoto são mais do que o triplo dos déficits à água;

- $\quad$ as 5 mesorregiões com maiores déficits de acesso a abastecimento de água (Jequitinhonha, Vale do Mucuri, Vale do Rio Doce, Noroeste de Minas e Norte de Minas) são aquelas que têm as menores urbanizações e os menores níveis de renda (Tabela 2) e são localizadas mais ao norte do estado, área tradicionalmente apontada na literatura como relativamente menos desenvolvida;

- $\quad$ as 4 mesorregiões com maiores déficits de acesso a esgoto estão entre as 5 com maiores déficits de a abastecimento de água (Norte de Minas, Jequitinhonha, Noroeste de Minas e Vale do Mucuri);

- $\quad$ as 2 mesorregiões com menores déficits de acesso aos dois serviços analisados (Metropolitana de Belo Horizonte e Triângulo Mineiro e Alto Paranaíba) são aquelas com as maiores taxas de urbanização, rendas domiciliares per capita e PIBs per capita (Tabela 2).

Como já mencionado, segmentos mais pobres da população têm menor probabilidade de ter acesso a saneamento. Nesse sentido, alguns trabalhos discutem a existência de desigualdades de acesso associadas à renda dos usuários (REZENDE et al. 2007; SAIANI; TONETO JÚNIOR, 2010; SAIANI et al., 2013a, 2013b). Para averiguar esta possibilidade no objeto deste estudo, são calculados indicadores de déficits de acesso a abastecimento de água e a coleta de esgoto para os domicílios "mais pobres" e "mais ricos". Em cada mesorregião - e no estado -, os domicílios são ordenados pelos rendimentos domiciliares per capita, identificando os quintis da distribuição; depois, são calculadas as proporções de domicílios sem acesso a cada um dos serviços nos $1^{\circ}$ e $5^{\circ}$ quintis da distribuição - "mais pobres" e "mais ricos", respectivamente.

A Tabela 4 apresenta ainda os déficits de acesso, em 2010, dos "mais pobres" e "mais ricos" $\left(5^{\circ}\right.$ quintil) em cada mesorregião. Nota-se que, no geral, os déficits de acesso dos "mais pobres" são quase o dobro aos dos "mais ricos" nos dois serviços. Tal evidência corrobora o argumento da literatura de que a capacidade de pagamento dos usuários afeta o acesso a serviços de saneamento. Ademais, nos dois grupos, os déficits do esgoto são superiores aos da água e os déficits por quintis seguem a tendência dos totais. Ou 
seja, as mesorregiões com menores déficits totais tendem a possuir os menores déficits por quintis e as com maiores déficits no total tendem a apresentar os maiores déficits por quintis (Tabelas 3 e 4).

Tabela 4 - Minas Gerais: déficits de acesso a saneamento básico, segundo os serviços, as mesorregiões e posições nos rankings (2010)

\begin{tabular}{|c|c|c|c|c|c|c|}
\hline \multirow[b]{2}{*}{ Mesorregiões } & \multicolumn{3}{|c|}{ Abastecimento de Água } & \multicolumn{3}{|c|}{ Coleta de Esgoto } \\
\hline & $\begin{array}{c}\% \text { dos } \\
\text { domicílios }\end{array}$ & $\begin{array}{c}\text { Mais } \\
\text { Pobres }\end{array}$ & $\begin{array}{l}\text { Mais } \\
\text { Ricos }\end{array}$ & $\begin{array}{c}\% \text { dos } \\
\text { domicílios }\end{array}$ & $\begin{array}{c}\text { Mais } \\
\text { Pobres }\end{array}$ & Mais Ricos \\
\hline Campo das Vertentes & 14,5 & 20,9 & 10,0 & 23,2 & 32,1 & 16,6 \\
\hline Central Mineira & 13,6 & 17,7 & 11,1 & 33,5 & 42,3 & 25,6 \\
\hline Jequitinhonha & 31,5 & 45,1 & 20,9 & 53,9 & 68,0 & 40,1 \\
\hline Metropolitana de Belo Horizonte & 5,1 & 7,2 & 3,6 & 16,1 & 22,3 & 11,0 \\
\hline Noroeste de Minas & 21,6 & 28,5 & 17,7 & 42,0 & 53,0 & 32,9 \\
\hline Norte de Minas & 21,3 & 29,9 & 15,0 & 67,0 & 73,5 & 59,9 \\
\hline Oeste de Minas & 10,9 & 15,5 & 8,0 & 16,4 & 23,4 & 11,1 \\
\hline Sul e Sudoeste de Minas & 18,0 & 25,2 & 12,5 & 20,2 & 27,7 & 14,4 \\
\hline Triângulo Mineiro e Alto Paranaíba & 9,9 & 13,4 & 9,0 & 12,9 & 18,1 & 10,6 \\
\hline Vale do Mucuri & 27,3 & 39,5 & 16,8 & 41,3 & 55,1 & 26,2 \\
\hline Vale do Rio Doce & 22,9 & 29,9 & 16,0 & 27,0 & 34,8 & 19,9 \\
\hline Zona da Mata & 19,3 & 28,5 & 12,2 & 25,2 & 34,4 & 17,4 \\
\hline Estado de Minas Gerais & 13,9 & 19,5 & 9,9 & $\mathbf{2 4 , 7}$ & 32,1 & 18,6 \\
\hline
\end{tabular}

Fonte: IBGE, Censo Demográfico de 2010. Elaboração própria.

\subsection{Evoluções dos déficits de acesso (1991 a 2010)}

A seguir, é avaliado como os déficits de acesso aos serviços de saneamento evoluíram de 1991 a 2010. A Tabela 5 mostra que os déficits de acesso a abastecimento de água e a coleta de esgoto reduziram no estado de Minas Gerais no período. Na água, a redução foi de 17,3 pontos percentuais $(55,45 \%)$; no esgoto, foi de 24,8 pontos percentuais $(50,1 \%)$. Verifica-se, ainda, que as reduções dos déficits de acesso foram maiores no abastecimento de água nas duas décadas, sendo observadas quedas de 27,6\% nos anos 1990 e $38,5 \%$ nos 2000, frente a reduções dos déficits de acesso a esgoto de, respectivamente, 23,6\% e 34,7\%.

Tabela 5 - Minas Gerais: evoluções dos déficits a abastecimento de água, segundo as mesorregiões, a década de maior redução e a posição no ranking de reduções (1991, 2000 e 2010)

\begin{tabular}{|c|c|c|c|c|c|c|c|c|}
\hline \multirow[b]{2}{*}{ Mesorregiões } & \multicolumn{3}{|c|}{ Déficit (\%) } & \multicolumn{3}{|c|}{ Variação $(\%)$} & \multirow{2}{*}{$\begin{array}{c}\text { Década com } \\
\text { Maior } \\
\text { Redução }\end{array}$} & \multirow[b]{2}{*}{ Ranking } \\
\hline & 1991 & 2000 & 2010 & $\begin{array}{c}1991 \text { a } \\
2000\end{array}$ & $\begin{array}{c}2000 \text { a } \\
2010\end{array}$ & $\begin{array}{c}1991 \text { a } \\
2010\end{array}$ & & \\
\hline Campo das Vertentes & 28,6 & 19,0 & 14,5 & $-33,4$ & $-24,0$ & $-49,4$ & 1990 & $5^{\circ}$ \\
\hline Central Mineira & 25,7 & 16,2 & 13,6 & $-37,2$ & $-16,0$ & $-47,3$ & 1990 & $6^{\circ}$ \\
\hline Jequitinhonha & 52,3 & 35,0 & 31,5 & $-33,1$ & $-9,8$ & $-39,7$ & 1990 & $10^{\circ}$ \\
\hline Metropolitana de Belo Horizonte & 13,2 & 7,1 & 5,1 & $-45,9$ & $-29,0$ & $-61,6$ & 1990 & $1^{\mathrm{o}}$ \\
\hline Noroeste de Minas & 38,2 & 25,1 & 21,6 & $-34,4$ & $-13,7$ & $-43,4$ & 1990 & $7^{\circ}$ \\
\hline Norte de Minas & 45,3 & 26,8 & 21,3 & $-40,7$ & $-20,8$ & $-53,1$ & 1990 & $2^{\circ}$ \\
\hline Oeste de Minas & 22,6 & 14,3 & 10,9 & $-36,7$ & $-23,9$ & $-51,8$ & 1990 & $3^{\circ}$ \\
\hline Sul e Sudoeste de Minas & 29,4 & 21,4 & 18,0 & $-27,2$ & $-15,9$ & $-38,8$ & 1990 & $11^{\circ}$ \\
\hline Triângulo Mineiro e Alto Paranaíba & 19,8 & 12,4 & 9,9 & $-37,5$ & $-19,7$ & $-49,8$ & 1990 & $4^{\circ}$ \\
\hline Vale do Mucuri & 44,1 & 31,4 & 27,3 & $-28,8$ & $-13,0$ & $-38,0$ & 1990 & $12^{\circ}$ \\
\hline Vale do Rio Doce & 38,1 & 28,1 & 22,9 & $-26,3$ & $-18,6$ & $-40,0$ & 1990 & $9^{\circ}$ \\
\hline Zona da Mata & 32,7 & 22,5 & 19,3 & $-31,1$ & $-14,4$ & $-41,0$ & 1990 & $8^{\circ}$ \\
\hline Estado de Minas Gerais & 31,2 & 22,6 & 13,9 & $-27,8$ & $-38,4$ & $-55,5$ & 2000 & -- \\
\hline
\end{tabular}

Fonte: IBGE, Censos Demográficos de 1991, 2000 e 2010. Elaboração própria.

Portanto, nota-se que as evoluções das coberturas dos dois serviços foram mais acentuadas na década de 2000. Essas evidências podem estar relacionadas, na década de 1990, ao término do Plano Nacional de Saneamento (Planasa) ${ }^{1}$, à desarticulação das políticas imediatamente posteriores e às restrições aos investimentos existentes no período (TUROLLA, 2002; TONETO JÚNIOR; SAIANI, 2006); já na década

\footnotetext{
${ }^{1}$ O Planasa, que vigorou de 1971 a 1992, foi um modelo de financiamento de investimentos no setor com recursos federais e centralização das decisões de repasse no Banco Nacional de Habitação (BNH) e da operação em Companhias Estaduais de Saneamento Básico (CESBs), sendo a água priorizada em detrimento do esgoto (MPO; IPEA, 1995; TUROLLA, 2002$).$
} 
de 2000, ao incentivo dos Objetivos do Desenvolvimento do Milênio (ODM), à promulgação da Lei do Saneamento e à alocação de mais recursos federais para investimentos no saneamento pelo Programa de Aceleração do Crescimento (BRASIL, 2007; MADEIRA, 2010; SNSA, 2011; SAIANI et al., 2015). Porém, como é avaliado a seguir, a década de 1990 é, no geral, a com maiores evoluções nas mesorregiões.

A Tabela 5 também mostra as evoluções dos déficits de acesso a água nas mesorregiões de Minas Gerais, a variação percentual década a década, em qual década houve maior redução e o ranking das maiores reduções no período total (da maior para a menor). É possível observar a ocorrência de reduções dos déficits de acesso a água em todas as mesorregiões e décadas. As quedas nas duas décadas oscilam entre $-61,6 \%$, na Metropolitana de Belo Horizonte (-8,1 pontos percentuais), e $-38 \%$ no Vale do Mucuri (-16,8 pontos percentuais). A Metropolitana de Belo Horizonte é a única com percentual de redução do déficit de acesso a água maior que a redução do estado de Minas Gerais no período total $(-55,5 \%)$ e, também, a mesorregião com a maior queda no período e o menor déficit em 2010. Já a Jequitinhonha tem os maiores déficits de acesso a água em todo o período analisado e uma das menores reduções percentuais deste déficit (-39,7\%).

Analisando por décadas, as maiores reduções dos déficits de acesso a água ocorreram na de $1990 \mathrm{em}$ todas as mesorregiões mineiras, variando de $-26,3 \%$ no Vale do Rio Doce ( -10 pontos percentuais) a $-45,9 \%$ na Metropolitana de Belo Horizonte (-6,1 pontos percentuais). Nesta década, apenas Vale do Rio Doce e Sul e Sudoeste de Minas apresentaram reduções do déficit de acesso a água abaixo da redução para todo o estado (-27,8\%). Nos anos de 2000, as quedas dos déficits foram menos acentuadas, oscilando de $-9,8 \%$ no Jequitinhonha (-3,4 pontos percentuais) a $-29 \%$ na Metropolitana de Belo Horizonte (-2,1 pontos percentuais). Ademais, na década, todas as mesorregiões apresentaram queda nos déficits abaixo do estado.

A Tabela 6 mostra as evoluções dos déficits de acesso a água, de 1991 a 2010, para os "mais pobres". Nota-se uma tendência de queda dos déficits de acesso dos "mais pobres". Como já antecipado, as reduções dos déficits ocorreram com maiores intensidades nos anos 1990 em todas as mesorregiões. Porém, nesta década, apenas as mesorregiões Central Mineira, Metropolitana de Belo Horizonte, Norte de Minas e Triângulo Mineiro e Alto Paranaíba tiveram reduções dos déficits acima da observada no total do estado. Já nos anos 2000, as mesorregiões com reduções dos déficits superiores à redução do total do estado foram Campo das Vertentes, Metropolitana de Belo Horizonte, Oeste de Minas e Triângulo Mineiro e Alto Paranaíba. Entre 1991 a 2010, todas as mesorregiões citadas em uma das décadas tiveram reduções dos déficits de água superiores à redução para o total do estado. Além disso, no geral, as quedas dos déficits de água não foram superiores às das mesorregiões em piores situações, como Jequitinhonha e Vale do Mucuri.

Tabela 6 - Minas Gerais: evoluções dos déficits dos "mais pobres" a abastecimento de água, segundo as mesorregiões, a década de maior redução e a posição no ranking de reduções (1991, 2000 e 2010)

\begin{tabular}{|c|c|c|c|c|c|c|c|c|}
\hline \multirow[b]{2}{*}{ Mesorregiões } & \multicolumn{3}{|c|}{ Déficit (\%) } & \multicolumn{3}{|c|}{ Variação $(\%)$} & \multirow{2}{*}{$\begin{array}{c}\text { Década com } \\
\text { Maior } \\
\text { Redução }\end{array}$} & \multirow[b]{2}{*}{ Ranking } \\
\hline & 1991 & 2000 & 2010 & $\begin{array}{c}1991 \text { a } \\
2000\end{array}$ & $\begin{array}{c}2000 \text { a } \\
2010\end{array}$ & $\begin{array}{c}1991 \text { a } \\
2010\end{array}$ & & \\
\hline Campo das Vertentes & 45,2 & 28,8 & 20,9 & $-36,3$ & $-27,4$ & $-53,8$ & 1990 & $4^{\circ}$ \\
\hline Central Mineira & 39,1 & 21,3 & 17,7 & $-45,5$ & $-16,9$ & $-54,7$ & 1990 & $2^{\circ}$ \\
\hline Jequitinhonha & 67,3 & 47,9 & 45,1 & $-28,8$ & $-5,8$ & $-33,0$ & 1990 & $11^{\circ}$ \\
\hline Metropolitana de Belo Horizonte & 22,5 & 11,0 & 7,2 & $-51,1$ & $-34,5$ & $-68,0$ & 1990 & $1^{\mathrm{o}}$ \\
\hline Noroeste de Minas & 53,3 & 34,7 & 28,5 & $-34,9$ & $-17,9$ & $-46,5$ & 1990 & $7^{\circ}$ \\
\hline Norte de Minas & 60,3 & 37,8 & 29,9 & $-37,3$ & $-20,9$ & $-50,4$ & 1990 & $6^{\circ}$ \\
\hline Oeste de Minas & 34,2 & 21,9 & 15,5 & $-36,0$ & $-29,2$ & $-54,7$ & 1990 & $3^{\circ}$ \\
\hline Sul e Sudoeste de Minas & 46,1 & 31,8 & 25,2 & $-31,0$ & $-20,8$ & $-45,3$ & 1990 & $8^{\circ}$ \\
\hline Triângulo Mineiro e Alto Paranaíba & 28,3 & 17,6 & 13,4 & $-37,8$ & $-23,9$ & $-52,7$ & 1990 & $5^{\circ}$ \\
\hline Vale do Mucuri & 58,4 & 44,9 & 39,5 & $-23,1$ & $-12,0$ & $-32,4$ & 1990 & $12^{\circ}$ \\
\hline Vale do Rio Doce & 53,7 & 38,3 & 29,9 & $-28,7$ & $-21,9$ & $-44,3$ & 1990 & $9^{\circ}$ \\
\hline Zona da Mata & 49,8 & 34,3 & 28,5 & $-31,1$ & $-16,9$ & $-42,8$ & 1990 & $10^{\circ}$ \\
\hline Estado de Minas Gerais & 39,8 & 25,0 & 19,4 & $-37,1$ & $-22,2$ & 51,1 & 1990 & - \\
\hline
\end{tabular}

Fonte: IBGE, Censos Demográficos de 1991, 2000 e 2010. Elaboração própria.

Já a Tabela 7 mostra as evoluções dos déficits de acesso a abastecimento de água dos domicílios "mais ricos" ( $5^{\circ}$ quintil da distribuição de rendimentos domiciliares). Assim como no total e $1^{\circ}$ quintil, em todas as mesorregiões as maiores reduções dos déficits ocorreram nos anos 1990. Nestes anos, as reduções dos déficits dos "mais ricos" nas mesorregiões Jequitinhonha, Metropolitana de Belo Horizonte, Norte de Minas, Oeste de Minas e Vale do Mucuri foram superiores à redução do déficit dos "mais ricos" no total 
de Minas Gerais. Vale ressaltar que Jequitinhonha, mesorregião com o maior déficit de acesso a água em 2010, apresentou uma das maiores reduções do déficit dos "mais ricos" nos anos 1990 e uma das menores reduções do déficit dos "mais pobres" nesta década. Nos anos 2000, as quedas dos déficits dos "mais ricos" nas mesorregiões Campo das Vertentes, Central Mineira, Metropolitana de Belo Horizonte, Oeste de Minas, Vale do Rio Doce e Zona da Mata foram superiores às quedas dos déficits dos "mais ricos" no estado.

Tabela 7 - Minas Gerais: evoluções dos déficits dos "mais ricos" a abastecimento de água, segundo as mesorregiões, a década de maior redução e a posição no ranking de reduções $(1991,2000$ e 2010)

\begin{tabular}{|c|c|c|c|c|c|c|c|c|}
\hline \multirow[b]{2}{*}{ Mesorregiões } & \multicolumn{3}{|c|}{ Déficit (\%) } & \multicolumn{3}{|c|}{ Variação (\%) } & \multirow{2}{*}{$\begin{array}{c}\text { Década com } \\
\text { Maior } \\
\text { Redução }\end{array}$} & \multirow[b]{2}{*}{ Ranking } \\
\hline & 1991 & 2000 & 2010 & $\begin{array}{c}1991 \text { a } \\
2000\end{array}$ & $\begin{array}{c}2000 \text { a } \\
2010\end{array}$ & $\begin{array}{c}1991 \text { a } \\
2010\end{array}$ & & \\
\hline Campo das Vertentes & 16,9 & 12,6 & 10,0 & $-25,4$ & $-20,6$ & $-40,8$ & 1990 & $4^{\circ}$ \\
\hline Central Mineira & 16,5 & 12,2 & 11,1 & $-26,1$ & $-9,0$ & $-32,7$ & 1990 & $8^{\circ}$ \\
\hline Jequitinhonha & 33,3 & 19,3 & 20,9 & $-42,0$ & 8,3 & $-37,2$ & 1990 & $6^{\circ}$ \\
\hline Metropolitana de Belo Horizonte & 7,6 & 4,2 & 3,6 & $-44,7$ & $-14,3$ & $-52,6$ & 1990 & $1^{\mathrm{o}}$ \\
\hline Noroeste de Minas & 25,7 & 18,5 & 17,7 & $-28,0$ & $-4,3$ & $-31,1$ & 1990 & $10^{\circ}$ \\
\hline Norte de Minas & 29,1 & 16,1 & 15,0 & $-44,7$ & $-6,8$ & $-48,5$ & 1990 & $2^{\circ}$ \\
\hline Oeste de Minas & 14,7 & 9,4 & 8,0 & $-36,1$ & $-14,9$ & $-45,6$ & 1990 & $3^{\circ}$ \\
\hline Sul e Sudoeste de Minas & 16,3 & 13,2 & 12,5 & $-19,0$ & $-5,3$ & $-23,3$ & 1990 & $12^{\circ}$ \\
\hline Triângulo Mineiro e Alto Paranaíba & 14,5 & 9,8 & 9,0 & $-32,4$ & $-8,2$ & $-37,9$ & 1990 & $5^{\circ}$ \\
\hline Vale do Mucuri & 26,5 & 15,7 & 16,8 & $-40,8$ & 7,0 & $-36,6$ & 1990 & $7^{\circ}$ \\
\hline Vale do Rio Doce & 22,4 & 18,3 & 16,0 & $-18,3$ & $-12,6$ & $-28,6$ & 1990 & $11^{\circ}$ \\
\hline Zona da Mata & 18,1 & 13,8 & 12,2 & $-23,8$ & $-11,6$ & $-32,6$ & 1990 & $9^{\circ}$ \\
\hline Estado de Minas Gerais & 16,2 & $\mathbf{1 0 , 8}$ & $\mathbf{9 , 8}$ & $-33,2$ & $-8,9$ & $-39,1$ & 1990 & - \\
\hline
\end{tabular}

Fonte: IBGE, Censos Demográficos de 1991, 2000 e 2010. Elaboração própria.

Entre 1991 a 2010, apenas Campo das Vertentes, Metropolitana de Belo Horizonte, Norte de Minas e Oeste de Minas tiveram reduções dos déficits superiores à redução do déficit do estado. Observa-se, ainda, que, ao contrário dos demais indicadores, os déficits expandiram nas mesorregiões do Jequitinhonha e do Vale do Mucuri na década de 2000, justamente as mesorregiões que apresentavam as piores situações de acesso a abastecimento de água e melhorias inferiores às das demais mesorregiões no período considerado.

A Tabela 8 mostra as evoluções, de 1991 a 2010, dos déficits de acesso a esgoto. Notam-se reduções dos déficits em todas mesorregiões. De 1991 a 2010, estas variaram de -59,2\% no Triângulo Mineiro e Alto Paranaíba (-18,7 pontos percentuais) a $-20,6 \%$ no Norte de Minas (-17,4 pontos percentuais). As maiores quedas ocorreram nas mesorregiões com os menores déficits em 2010, como Triângulo Mineiro e Alto Paranaíba, Oeste de Minas e Metropolitana de Belo Horizonte. Já a Norte de Minas e o Jequitinhonha apresentaram as menores quedas e são as mesorregiões com os maiores déficits em 2010. As maiores reduções dos déficits ocorreram nos anos 1990 em quase todas as mesorregiões, exceto o Noroeste de Minas e Norte de Minas. Nestes anos, as reduções variaram de $-45 \%$ no Triângulo Mineiro e Alto Paranaíba a 10,8\% no Norte de Minas e apenas Noroeste de Minas (-21,5\%), Jequitinhonha (-20,8\%) e Norte de Minas $(-10,8 \%)$ apresentaram reduções dos déficits a esgoto abaixo do estado (-23,7\%). Nos anos 2000, as reduções nos déficits foram menos acentuadas, oscilando de $-32,2 \%$ no Oeste de Minas a $-11 \%$ no Norte de Minas e, em todas as mesorregiões, as reduções foram menores do que no estado de Minas Gerais.

A Tabela 9 mostra as evoluções, 1991 a 2010, dos déficits de acesso a coleta de esgoto nos "mais pobres". No período total, assim como em cada década, em 9 das 12 mesorregiões as maiores reduções dos déficits de acesso a esgoto ocorreram na década de 1990 - excetuando-se Metropolitana de Belo Horizonte, Noroeste de Minas e Vale do Rio Doce. Entre 1991 e 2010, apenas as mesorregiões Campo das Vertentes, Metropolitana de Belo Horizonte, Oeste de Minas, Sul e Sudoeste de Minas e Triângulo Mineiro e Alto Paranaíba apresentaram reduções dos déficits a esgoto dos "mais pobres" superiores à redução do déficit do estado. Além disso, as maiores reduções dos déficits não ocorreram nas mesorregiões mais deficitárias.

Para os "mais ricos", a Tabela 10 mostra que os déficits de acesso a esgoto reduziram-se no período e nas 2 décadas, em todas as mesorregiões, sendo que em 10 as maiores quedas dos déficits ocorreram nos anos 1990, exceto Noroeste de Minas e Norte de Minas. As reduções, nos anos 1990, em quase todas as mesorregiões, foram superiores à do estado. Já nos anos 2000, apenas as mesorregiões Central Mineira, Metropolitana de Belo Horizonte, Noroeste de Minas, Oeste de Minas e Vale do Rio Doce apresentaram reduções dos déficits a coleta de esgoto dos "mais ricos" maiores que a redução deste déficit no estado. 
Tabela 8 - Minas Gerais: evoluções dos déficits a coleta de esgoto, segundo as mesorregiões, a década de maior redução e a posição no ranking de reduções $(1991,2000$ e 2010)

\begin{tabular}{|c|c|c|c|c|c|c|c|c|}
\hline \multirow[b]{2}{*}{ Mesorregiões } & \multicolumn{3}{|c|}{ Déficit (\%) } & \multicolumn{3}{|c|}{ Variação $(\%)$} & \multirow{2}{*}{$\begin{array}{c}\text { Década com } \\
\text { Maior } \\
\text { Redução } \\
\end{array}$} & \multirow[b]{2}{*}{ Ranking } \\
\hline & 1991 & 2000 & 2010 & $\begin{array}{c}1991 \text { a } \\
2000\end{array}$ & $\begin{array}{c}2000 \text { a } \\
2010\end{array}$ & $\begin{array}{c}1991 \text { a } \\
2010\end{array}$ & & \\
\hline Campo das Vertentes & 44,4 & 29,3 & 23,2 & $-34,0$ & $-20,8$ & $-47,7$ & 1990 & $5^{\circ}$ \\
\hline Central Mineira & 61,9 & 42,2 & 33,5 & $-31,8$ & $-20,5$ & $-45,8$ & 1990 & $6^{\mathrm{o}}$ \\
\hline Jequitinhonha & 82,9 & 65,7 & 53,9 & $-20,8$ & $-18,0$ & $-35,0$ & 1990 & $11^{\circ}$ \\
\hline Metropolitana de Belo Horizonte & 34,0 & 23,2 & 16,1 & $-31,7$ & $-30,9$ & $-52,8$ & 1990 & $3^{\circ}$ \\
\hline Noroeste de Minas & 70,4 & 55,3 & 42,0 & $-21,5$ & $-24,0$ & $-40,3$ & 2000 & $8^{\circ}$ \\
\hline Norte de Minas & 84,4 & 75,3 & 67,0 & $-10,8$ & $-11,0$ & $-20,6$ & 2000 & $12^{\circ}$ \\
\hline Oeste de Minas & 39,5 & 24,2 & 16,4 & $-38,6$ & $-32,2$ & $-58,4$ & 1990 & $2^{\circ}$ \\
\hline Sul e Sudoeste de Minas & 36,6 & 24,8 & 20,2 & $-32,2$ & $-18,5$ & $-44,8$ & 1990 & $7^{\circ}$ \\
\hline Triângulo Mineiro e Alto Paranaíba & 31,6 & 17,4 & 12,9 & $-45,0$ & $-25,7$ & $-59,2$ & 1990 & $1^{\mathrm{o}}$ \\
\hline Vale do Mucuri & 68,7 & 49,3 & 41,3 & $-28,2$ & $-16,2$ & $-39,8$ & 1990 & $9^{\circ}$ \\
\hline Vale do Rio Doce & 54,5 & 38,1 & 27,0 & $-30,0$ & $-29,3$ & $-50,5$ & 1990 & $4^{\mathrm{o}}$ \\
\hline Zona da Mata & 41,5 & 28,9 & 25,2 & $-30,4$ & $-12,9$ & $-39,4$ & 1990 & $10^{\circ}$ \\
\hline Estado de Minas Gerais & 49,5 & $\mathbf{3 7 , 8}$ & $\mathbf{2 4 , 7}$ & $-23,7$ & $-34,6$ & $-50,1$ & 2000 & -- \\
\hline
\end{tabular}

Fonte: IBGE, Censos Demográficos de 1991, 2000 e 2010. Elaboração própria.

Tabela 9 - Minas Gerais: evoluções dos déficits dos "mais pobres" a coleta de esgoto, segundo as mesorregiões, a década de maior redução e a posição no ranking de reduções (1991, 2000 e 2010)

\begin{tabular}{|c|c|c|c|c|c|c|c|c|}
\hline \multirow[b]{2}{*}{ Mesorregiões } & \multicolumn{3}{|c|}{ Déficit (\%) } & \multicolumn{3}{|c|}{ Variação $(\%)$} & \multirow{2}{*}{$\begin{array}{c}\text { Década com } \\
\text { Maior } \\
\text { Redução }\end{array}$} & \multirow[b]{2}{*}{ Ranking } \\
\hline & 1991 & 2000 & 2010 & $\begin{array}{c}1991 \text { a } \\
2000\end{array}$ & $\begin{array}{c}2000 \mathrm{a} \\
2010\end{array}$ & $\begin{array}{c}1991 \text { a } \\
2010\end{array}$ & & \\
\hline Campo das Vertentes & 63,9 & 40,7 & 32,1 & $-36,3$ & $-21,1$ & $-49,8$ & 1990 & $5^{\circ}$ \\
\hline Central Mineira & 76,3 & 55,0 & 42,3 & $-27,9$ & $-23,1$ & $-44,6$ & 1990 & $6^{\mathrm{o}}$ \\
\hline Jequitinhonha & 93,3 & 79,2 & 68,0 & $-15,1$ & $-14,1$ & $-27,1$ & 1990 & $10^{\circ}$ \\
\hline Metropolitana de Belo Horizonte & 52,3 & 34,2 & 22,3 & $-34,6$ & $-34,8$ & $-57,4$ & 2000 & $3^{\circ}$ \\
\hline Noroeste de Minas & 86,7 & 69,5 & 53,0 & $-19,8$ & $-23,7$ & $-38,9$ & 2000 & $8^{\circ}$ \\
\hline Norte de Minas & 91,4 & 81,7 & 73,5 & $-10,6$ & $-10,0$ & $-19,6$ & 1990 & $11^{\circ}$ \\
\hline Oeste de Minas & 57,1 & 36,4 & 23,4 & $-36,3$ & $-35,7$ & $-59,0$ & 1990 & $2^{\circ}$ \\
\hline Sul e Sudoeste de Minas & 55,2 & 36,0 & 27,7 & $-34,8$ & $-23,1$ & $-49,8$ & 1990 & $5^{\circ}$ \\
\hline Triângulo Mineiro e Alto Paranaíba & 47,0 & 25,2 & 18,1 & $-46,4$ & $-28,2$ & $-61,5$ & 1990 & $1^{\circ}$ \\
\hline Vale do Mucuri & 84,4 & 65,0 & 55,1 & $-23,0$ & $-15,2$ & $-34,7$ & 1990 & $9^{\circ}$ \\
\hline Vale do Rio Doce & 72,1 & 50,2 & 34,8 & $-30,4$ & $-30,7$ & $-51,7$ & 2000 & $4^{\circ}$ \\
\hline Zona da Mata & 58,9 & 40,4 & 34,4 & $-31,4$ & $-14,9$ & $-41,6$ & 1990 & $7^{\circ}$ \\
\hline Estado de Minas Gerais & 61,5 & 42,4 & 32,1 & $-31,1$ & $-24,2$ & $-47,8$ & 1990 & - \\
\hline
\end{tabular}

Fonte: IBGE, Censos Demográficos de 1991, 2000 e 2010. Elaboração própria.

Tabela 10 - Minas Gerais: evoluções dos déficits dos "mais ricos" a coleta de esgoto, segundo as mesorregiões, a década de maior redução e a posição no ranking de reduções (1991, 2000 e 2010)

\begin{tabular}{|c|c|c|c|c|c|c|c|c|}
\hline \multirow[b]{2}{*}{ Mesorregiões } & \multicolumn{3}{|c|}{ Déficit (\%) } & \multicolumn{3}{|c|}{ Variação $(\%)$} & \multirow{2}{*}{$\begin{array}{c}\text { Década com } \\
\text { Maior } \\
\text { Redução } \\
\end{array}$} & \multirow[b]{2}{*}{ Ranking } \\
\hline & 1991 & 2000 & 2010 & $\begin{array}{c}1991 \text { a } \\
2000\end{array}$ & $\begin{array}{c}2000 \mathrm{a} \\
2010\end{array}$ & $\begin{array}{c}1991 \text { a } \\
2010\end{array}$ & & \\
\hline Campo das Vertentes & 28,1 & 18,9 & 16,6 & $-32,7$ & $-12,2$ & $-40,9$ & 1990 & $6^{\circ}$ \\
\hline Central Mineira & 44,3 & 30,1 & 25,6 & $-32,1$ & $-15,0$ & $-42,2$ & 1990 & $5^{\circ}$ \\
\hline Jequitinhonha & 65,2 & 47,0 & 40,1 & $-27,9$ & $-14,7$ & $-38,5$ & 1990 & $7^{\mathrm{o}}$ \\
\hline Metropolitana de Belo Horizonte & 18,6 & 13,8 & 11,0 & $-25,8$ & $-20,3$ & $-40,9$ & 1990 & $6^{\circ}$ \\
\hline Noroeste de Minas & 49,0 & 40,2 & 32,9 & $-18,0$ & $-18,2$ & $-32,9$ & 2000 & $9^{\circ}$ \\
\hline Norte de Minas & 76,0 & 68,9 & 59,9 & $-9,3$ & $-13,1$ & $-21,2$ & 2000 & $11^{\circ}$ \\
\hline Oeste de Minas & 23,0 & 14,5 & 11,1 & $-37,0$ & $-23,4$ & $-51,7$ & 1990 & $1^{\mathrm{o}}$ \\
\hline Sul e Sudoeste de Minas & 20,4 & 15,4 & 14,4 & $-24,5$ & $-6,5$ & $-29,4$ & 1990 & $10^{\circ}$ \\
\hline Triângulo Mineiro e Alto Paranaíba & 18,6 & 11,9 & 10,6 & $-36,0$ & $-10,9$ & $-43,0$ & 1990 & $2^{\circ}$ \\
\hline Vale do Mucuri & 45,5 & 29,6 & 26,2 & $-34,9$ & $-11,5$ & $-42,4$ & 1990 & $4^{\mathrm{o}}$ \\
\hline Vale do Rio Doce & 34,7 & 25,6 & 19,9 & $-26,2$ & $-22,3$ & $-42,7$ & 1990 & $3^{\circ}$ \\
\hline Zona da Mata & 26,0 & 19,4 & 17,4 & $-25,4$ & $-10,3$ & $-33,1$ & 1990 & $8^{\circ}$ \\
\hline Estado de Minas Gerais & 29,4 & 21,8 & 18,6 & $-25,6$ & $-14,9$ & $-36,7$ & 1990 & - \\
\hline
\end{tabular}

Fonte: IBGE, Censos Demográficos de 1991, 2000 e 2010. Elaboração própria. 


\subsection{Convergências dos acessos (1991 a 2010): reduções das desigualdades}

A seguir, é avaliado se, de 1991 a 2010, houve convergências, mesmo incompletas, do acesso aos serviços de saneamento em Minas Gerais. As convergências são analisadas por dois critérios: i) redução da diferença entre os déficits de uma mesorregião e o da Metropolitana de Belo Horizonte, tomada como base por ter o menor déficit a abastecimento de água e o $2^{\circ}$ menor a coleta de esgoto (Tabela 4); e ii) redução, em cada serviço e mesorregião, da diferença dos déficits dos domicílios "mais pobres" e "mais ricos".

Pelo primeiro critério, a Tabela 11 mostra as diferenças - em pontos percentuais (p.p.) - dos déficits de acesso a água nas mesorregiões relativamente à de referência. Observa-se convergência incompleta em todas as mesorregiões mineiras. As maiores convergências ocorreram nos anos 1990, o que, em conjunto com evidências anteriores, sinaliza perda de "força" para atingir a universalização do acesso nos anos 2000.

Tabela 11 - Minas Gerais: convergências dos déficits de acesso a abastecimento de água, segundo as mesorregiões (1991, 2000 e 2010)

\begin{tabular}{|c|c|c|c|c|c|c|c|}
\hline \multirow[b]{2}{*}{ Mesorregiões } & \multicolumn{3}{|c|}{ Diferença (p.p.) } & \multirow{2}{*}{$\begin{array}{c}\text { Convergência? } \\
\text { (Diferença 2010 < } \\
\text { Diferença 1991) }\end{array}$} & \multicolumn{2}{|c|}{ Variação (\%) } & \multirow{2}{*}{$\begin{array}{c}\text { Década com } \\
\text { Maior } \\
\text { Redução } \\
\end{array}$} \\
\hline & 1991 & 2000 & 2010 & & $\begin{array}{c}1991 \text { a } \\
2000\end{array}$ & $\begin{array}{c}2000 \text { a } \\
2010\end{array}$ & \\
\hline Campo das Vertentes & 15,4 & 11,9 & 9,4 & Sim & $-22,8$ & $-21,0$ & 1990 \\
\hline Central Mineira & 12,6 & 9,0 & 8,5 & Sim & $-28,1$ & $-5,8$ & 1990 \\
\hline Jequitinhonha & 39,1 & 27,8 & 26,5 & Sim & $-28,8$ & $-4,9$ & 1990 \\
\hline Noroeste de Minas & 25,0 & 18,0 & 16,6 & Sim & $-28,3$ & $-7,7$ & 1990 \\
\hline Norte de Minas & 32,1 & 19,7 & 16,2 & Sim & $-38,6$ & $-17,8$ & 1990 \\
\hline Oeste de Minas & 9,4 & 7,2 & 5,9 & Sim & $-23,7$ & $-18,8$ & 1990 \\
\hline Sul e Sudoeste de Minas & 16,2 & 14,2 & 12,9 & Sim & $-12,0$ & $-9,3$ & 1990 \\
\hline Triângulo Mineiro e Alto Paranaíba & 6,6 & 5,2 & 4,9 & Sim & $-20,5$ & $-7,0$ & 1990 \\
\hline Vale do Mucuri & 30,9 & 24,3 & 22,3 & Sim & $-21,5$ & $-8,3$ & 1990 \\
\hline Vale do Rio Doce & 24,9 & 21,0 & 17,8 & Sim & $-15,8$ & $-15,0$ & 1990 \\
\hline Zona da Mata & 19,5 & 15,4 & 14,3 & Sim & $-21,0$ & $-7,6$ & 1990 \\
\hline
\end{tabular}

Fonte: IBGE, Censos Demográficos de 1991, 2000 e 2010. Elaboração própria. Observação: p.p. - pontos percentuais.

A mesorregião de Jequitinhonha é emblemática: tem o maior déficit de acesso a água e a diferença do déficit de acesso em relação à Metropolitana caiu 28,8\% (-11,28 pontos percentuais) nos anos 1990, mas apenas 4,92\% (-1,37 pontos percentuais) nos anos 2000. Vale reforçar que as convergências ocorreram em intensidades distintas. Por exemplo, no Norte de Minas, a convergência nos anos 1990 foi superior às do Vale do Mucuri, Vale do Rio Doce e Noroeste de Minas. No Triângulo Mineiro e Oeste de Minas, as quedas das diferenças dos déficits foram menores, até porque seus déficits são próximos ao da região metropolitana.

No esgoto, segundo a Tabela 12, a tendência de convergência incompleta não é tão acentuada como na água. Por exemplo, Norte de Minas, Zona da Mata e Sul e Sudoeste de Minas apresentaram aumento da diferença de seus déficits em relação à região metropolitana no período total. No Triângulo Mineiro e Alto do Paranaíba, o mesmo é observado, mas como esta mesorregião tem déficits inferiores aos de referência, o sinal da diferença é invertido. O destaque negativo é a do Norte de Minas, com diferença de 51 pontos percentuais em 2010; já o positivo é o Oeste de Minas, com expressiva queda do déficit, praticamente se igualando à região metropolitana. Em quase todas as mesorregiões, a convergência foi maior nos anos 1990.

Pelo segundo critério adotado (redução da diferença dos déficits dos "mais pobres" e "mais ricos"), na água, a Tabela 14 mostra que houve, de 1991 a 2010, convergência incompleta em todas as mesorregiões e no estado. Assim, como são observadas reduções dos déficits nos dois quintis de rendimentos domiciliares em todas as mesorregiões mineiras (Tabelas 6 e 7), as reduções dos déficits de acesso a abastecimento de água dos "mais pobres" foram superiores às dos déficits dos "mais pobres". Em 9 das 12 mesorregiões e no estado, as convergências foram maiores nos anos 1990. Vale destacar as convergências na Central Mineira, na Metropolitana de Belo Horizonte, no Oeste de Minas e no Triângulo Mineiro e Alto do Paranaíba.

A convergência do acesso entre "mais pobres" e "mais ricos" no esgoto é apresentada na Tabela 14. As diferenças dos déficits entre "pobres" e "ricos" são menores em 2010 do que em 1991. Como os déficits a esgoto em todas as mesorregiões e nos 2 quintis cairam de 1991 a 2010 (Tabelas 9 e 10), as quedas das diferenças decorrem de maiores reduções nos "mais pobres". As maiores convergências foram nos anos 2000 na maioria das mesorregiões. Em mesorregiões bem deficitárias, houve períodos de divergências dos acessos entre "mais pobre" e "mais ricos" - Jequitinhonha nos anos 1990 e Norte de Minas nos anos 2000. 
Tabela 12 - Minas Gerais: convergências dos déficits de acesso a coleta de esgoto, segundo as mesorregiões (1991, 2000 e 2010)

\begin{tabular}{|c|c|c|c|c|c|c|c|}
\hline \multirow[b]{2}{*}{ Mesorregiões } & \multicolumn{3}{|c|}{ Diferença (p.p.) } & \multirow{2}{*}{$\begin{array}{c}\text { Convergência? } \\
\text { (Diferença 2010 < } \\
\text { Diferença 1991) }\end{array}$} & \multicolumn{2}{|c|}{ Variação (\%) } & \multirow{2}{*}{$\begin{array}{c}\text { Década com } \\
\text { Maior } \\
\text { Redução }\end{array}$} \\
\hline & 1991 & 2000 & 2010 & & $\begin{array}{c}1991 \text { a } \\
2000\end{array}$ & $\begin{array}{c}2000 \text { a } \\
2010\end{array}$ & \\
\hline Campo das Vertentes & 10,4 & 6,1 & 7,2 & Sim & $-41,4$ & $-17,6$ & 1990 \\
\hline Central Mineira & 27,8 & 18,9 & 17,5 & Sim & $-32,0$ & 7,7 & 1990 \\
\hline Jequitinhonha & 48,9 & 42,4 & 37,8 & Sim & $-13,2$ & $-10,9$ & 1990 \\
\hline Noroeste de Minas & 36,4 & 32,0 & 26,0 & Sim & $-11,9$ & $-19,0$ & 2000 \\
\hline Norte de Minas & 50,4 & 52,1 & 51,0 & Não & 3,4 & $-2,1$ & 1990 \\
\hline Oeste de Minas & 5,5 & 1,0 & 0,4 & Sim & $-81,8$ & $-62,0$ & 1990 \\
\hline Sul e Sudoeste de Minas & 2,6 & 1,6 & 4,2 & Não & $-39,0$ & 163,4 & 1990 \\
\hline Triângulo Mineiro e Alto Paranaíba & $-2,4$ & $-5,9$ & $-3,2$ & Não & 141,8 & $-46,4$ & 2000 \\
\hline Vale do Mucuri & 34,7 & 26,1 & 25,3 & Sim & $-24,8$ & $-3,1$ & 1990 \\
\hline Vale do Rio Doce & 20,4 & 14,9 & 10,9 & Sim & $-27,3$ & $-26,7$ & 1990 \\
\hline Zona da Mata & 7,5 & 5,7 & 9,1 & Não & $-24,7$ & 61,3 & 1990 \\
\hline
\end{tabular}

Fonte: IBGE, Censos Demográficos de 1991, 2000 e 2010. Elaboração própria. Observação: p.p. - pontos percentuais.

Tabela 13 - Minas Gerais: convergências dos déficits a abastecimento de água entre os "mais pobres" e os "mais ricos", segundo as mesorregiões $(1991,2000$ e 2010)

\begin{tabular}{|c|c|c|c|c|c|c|c|}
\hline \multirow[b]{2}{*}{ Mesorregiões } & \multicolumn{3}{|c|}{ Diferença (p.p.) } & \multirow{2}{*}{$\begin{array}{c}\text { Convergência? } \\
\text { (Diferença 2010 < } \\
\text { Diferença 1991) }\end{array}$} & \multicolumn{2}{|c|}{ Variação (\%) } & \multirow{2}{*}{$\begin{array}{c}\text { Década com } \\
\text { Maior } \\
\text { Redução } \\
\end{array}$} \\
\hline & 1991 & 2000 & 2010 & & $\begin{array}{c}1991 \text { a } \\
2000\end{array}$ & $\begin{array}{c}2000 \text { a } \\
2010\end{array}$ & \\
\hline Campo das Vertentes & 28,3 & 16,2 & 10,9 & Sim & $-42,8$ & $-32,7$ & 1990 \\
\hline Central Mineira & 22,7 & 9,1 & 6,6 & $\operatorname{Sim}$ & $-59,9$ & $-27,5$ & 1990 \\
\hline Jequitinhonha & 34,0 & 28,7 & 24,3 & Sim & $-15,6$ & $-15,3$ & 1990 \\
\hline Metropolitana de Belo Horizonte & 14,9 & 6,9 & 3,6 & Sim & $-53,7$ & $-47,8$ & 1990 \\
\hline Noroeste de Minas & 27,6 & 16,2 & 10,8 & Sim & $-41,3$ & $-33,3$ & 1990 \\
\hline Norte de Minas & 31,2 & 21,7 & 14,9 & Sim & $-30,4$ & $-31,3$ & 2000 \\
\hline Oeste de Minas & 19,6 & 12,5 & 7,5 & Sim & $-36,2$ & $-40,0$ & 2000 \\
\hline Sul e Sudoeste de Minas & 29,8 & 18,6 & 12,6 & Sim & $-37,6$ & $-32,3$ & 1990 \\
\hline Triângulo Mineiro e Alto Paranaíba & 13,9 & 7,8 & 4,4 & Sim & $-43,9$ & $-43,6$ & 1990 \\
\hline Vale do Mucuri & 31,9 & 29,2 & 22,6 & Sim & $-8,5$ & $-22,6$ & 2000 \\
\hline Vale do Rio Doce & 31,3 & 20,0 & 13,9 & Sim & $-36,1$ & $-30,5$ & 1990 \\
\hline Zona da Mata & 31,7 & 20,4 & 16,3 & Sim & $-35,6$ & $-20,1$ & 1990 \\
\hline Estado de Minas Gerais & $\mathbf{2 3 , 5}$ & 14,1 & 9,5 & Sim & $-39,9$ & 32,4 & 1990 \\
\hline
\end{tabular}

Fonte: IBGE, Censos Demográficos de 1991, 2000 e 2010. Elaboração própria. Observação: p.p. - pontos percentuais.

Tabela 14 - Minas Gerais: convergências dos déficits a coleta de esgoto entre os "mais pobres" e os "mais ricos", segundo as mesorregiões (1991, 2000 e 2010)

\begin{tabular}{|c|c|c|c|c|c|c|c|}
\hline \multirow[b]{2}{*}{ Mesorregiões } & \multicolumn{3}{|c|}{ Diferença (p.p.) } & \multirow{2}{*}{$\begin{array}{c}\text { Convergência? } \\
\text { (Diferença 2010 < } \\
\text { Diferença 1991) }\end{array}$} & \multicolumn{2}{|c|}{ Variação (\%) } & \multirow{2}{*}{$\begin{array}{c}\text { Década com } \\
\text { Maior } \\
\text { Reducão }\end{array}$} \\
\hline & 1991 & 2000 & 2010 & & $\begin{array}{c}1991 \text { a } \\
2000\end{array}$ & $\begin{array}{c}2000 \text { a } \\
2010\end{array}$ & \\
\hline Campo das Vertentes & 35,8 & 21,7 & 15,5 & Sim & $-39,4$ & $-28,6$ & 1990 \\
\hline Central Mineira & 32,0 & 24,8 & 16,6 & Sim & $-22,5$ & $-33,1$ & 2000 \\
\hline Jequitinhonha & 28,1 & 32,2 & 27,8 & Sim & 14,6 & $-13,7$ & 2000 \\
\hline Metropolitana de Belo Horizonte & 33,7 & 20,4 & 11,3 & Sim & $-39,5$ & $-44,6$ & 2000 \\
\hline Noroeste de Minas & 37,6 & 29,3 & 20,1 & Sim & $-22,1$ & $-31,4$ & 2000 \\
\hline Norte de Minas & 15,4 & 12,8 & 13,6 & Sim & $-16,9$ & 6,2 & 1990 \\
\hline Oeste de Minas & 34,1 & 21,9 & 12,3 & Sim & $-35,8$ & $-43,8$ & 2000 \\
\hline Sul e Sudoeste de Minas & 34,8 & 20,6 & 13,2 & Sim & $-40,8$ & $-35,9$ & 1990 \\
\hline Triângulo Mineiro e Alto Paranaíba & 28,4 & 13,3 & 7,5 & Sim & $-53,2$ & $-43,6$ & 1990 \\
\hline Vale do Mucuri & 39,0 & 35,4 & 28,9 & Sim & $-9,2$ & $-18,4$ & 2000 \\
\hline Vale do Rio Doce & 37,4 & 24,6 & 14,9 & Sim & $-34,2$ & $-39,4$ & 2000 \\
\hline Zona da Mata & 32,9 & 20,9 & 17,0 & Sim & $-36,5$ & $-18,7$ & 1990 \\
\hline Estado de Minas Gerais & 32,1 & 20,5 & 13,5 & Sim & $-36,1$ & $-34,1$ & 1990 \\
\hline
\end{tabular}

Fonte: IBGE, Censos Demográficos de 1991, 2000 e 2010. Elaboração própria. Observação: p.p. - pontos percentuais.

Portanto, as análises das convergências sinalizam que as desigualdades de acesso a abastecimento de água e a coleta de esgoto reduziram de 1991 a 2010, tanto em termos de diferenças entre as mesorregiões como entre os "mais pobres" e "mais ricos". Ademais, considerando em conjunto todas as evidências até aqui, é possível sugerir que as reduções dos déficits e de suas desigualdades foram maiores nos anos 1990. 


\section{Saneamento básico e Objetivos de Desenvolvimento Sustentável (ODSs)}

\subsection{A importância do saneamento para o cumprimento dos ODSs}

Em 2015, sob o legado dos "Objetivos de Desenvolvimento do Milênio" (ODMs), a ONU realizou a "Cimeira do Desenvolvimento Sustentável”, na qual líderes de vários países, inclusive do Brasil, definiram os principais objetivos para direcionar o mundo a um caminho sustentável, sendo firmado um plano de intenções para o cumprimento de "17 Objetivos de Desenvolvimento Sustentável" (ODSs) e 169 metas a serem atingidas, no geral, até 2030. Os ODSs e as metas são chamadas de "Agenda 2030" (ONU, 2015).

Pela literatura sobre o tema, pode-se defender pelo menos 12 ODSs e 32 metas como relacionados, direta e indiretamente, a reduções dos déficits de acesso aos serviços de saneamento básico, como causas e/ou consequências. Estes ODSs e metas (resumidamente) são apontados no Quadro 1. Primeiramente, vale destacar o "Objetivo 6" e as metas relacionadas, que tratam diretamente dos serviços de saneamento em várias dimensões, desde o acesso (metas 6.1 e 6.2), objeto deste estudo, até questões de qualidade, eficiência e gestão (metas 6.3, 6.4, 6.5, 6.a e 6.b) - também problemáticas no país (SAMPAIO; SAMPAIO, 2007). A meta 6.6 refere-se a um provável efeito negativo de inadequações dos serviços de saneamento sobre o meio ambiente. A dimensão ambiental também é preocupação dos ODSs 12, 14 e 15, nas metas 12.1, 14.1 e 15.1.

Nesse sentido, é importante apontar que condições inadequadas do saneamento básico contribuem para contaminações de mananciais, de cursos de água e dos solos, assim como para o assoreamento de rios e enchentes (CAIRNCROSS, 1984). Tais problemas se refletem em aspectos que afetam o desenvolvimento sustentável. Por um lado, para cidades e comunidades sustentáveis (ODS 11), é fundamental o acesso a saneamento, garantindo habitações mais seguras e urbanização sustentável (metas 11.1 e 11.3), reduzindo óbitos e número de pessoas afetadas por catástrofes, como é enchentes (meta 11.5). Vale considerar, ainda, que a poluição de recursos hídricos prejudica diretamente a produção de bens, em especial na agricultura, afetando o alcance do ODS 2 no que se refere à agricultura sustentável (meta 2.3), tanto que é definida uma meta (2.a) que trata especificamente da necessidade de aumentar investimentos em infraestrutura rural.

A meta 9.1 também trata de infraestrutura: "desenvolver infraestrutura de qualidade, confiável, sustentável e resiliente para apoiar o desenvolvimento econômico e o bem-estar humano". Tal meta está associada ao ODS 9 ("indústria, inovação e infraestrutura") e à discussão apresentada na introdução do abastecimento de água influenciar a PTF das empresas industriais e dos serviços de saneamento básico em geral, pelo canal da saúde (contração de doenças e internações), a produtividade de seus trabalhadores.

Solos e recursos hídricos contaminados e áreas alagadas são ambientes propícios à proliferação de agentes patogênicos de várias doenças. Crianças, em especial as de até 5 anos, são mais suscetíveis a estas doenças, devido aos estágios de desenvolvimento fisiológicos (sistema imunológico em formação), à maior ingestão de água e alimentos relativamente ao peso corpóreo, ao hábito de levarem mãos e objetos à boca e à maior proximidade ao chão (CVJETANOVIC, 1986; VICTORA et al., 1994; HELLER, 1997). Assim, o saneamento é fundamental para o alcance do ODS 3 e metas de saúde e bem-estar (3.1, 3.2, 3.3 e 3.9).

Pelo canal da saúde, os serviços de saneamento também podem contribuir para o cumprimento dos ODSs 4 e 8 e de suas metas $(4.1,4.2,8.1,8.2$ e 8.9) relacionadas à educação, ao trabalho e ao crescimento. Isto porque alguns trabalhos defendem, inclusive com evidências, que a contração de doenças na infância pode prejudicar o desenvolvimento físico e mental e, assim, o desempenho escolar das crianças e, nos adultos, a produtividade no trabalho (CVJETANOVIC, 1986; GLEWWE; JACOBY, 1995; PNUD, 2006).

O desenvolvimento humano pode ser entendido como processo de extinção de privações à liberdade (SEN, 1996, 2000, 2001; NUSSBAUM, 2011). Assim, nesta visão, inadequações do saneamento podem são dimensões importantes para o desenvolvimento, pois, ao afetarem a saúde e as condições objetivas do se "viver bem" (privações à saúde), também afetam a capacidade de realizar escolhas (capacitações individuais). Assim, o saneamento é fundamental para a redução de desigualdades (ODS 10), garantindo a igualdade de oportunidades e a redução de desigualdades de resultados (meta 10.3). Por todos os aspectos comentados até aqui, também é plausível supor que a adequação do saneamento seja importante para o ODS 1 e suas metas $(1.1,1.2$ e 1.4) relativas à erradicação da pobreza. Leipziger at al. (2003), avaliando os ODMs, anteriores aos ODSs, defende que objetivos referentes à renda resultariam no cumprimento dos demais. Porém, políticas para outros objetivos também são importantes, em especial às de saneamento. 
Quadro 1 - ODSs e metas relacionados, direta ou indiretamente, a reduções dos déficits de acesso a abastecimento de água e coleta de esgoto Objetivos

1. Erradicação da Pobreza

2. Fome Zero e Agricultura Sustentável

3. Saúde e Bem-Estar

4. Educação de Qualidade

6. Água Potável e Saneamento

8. Trabalho Decente e

Crescimento Econômico

9. Indústria, Inovação e

Infraestrutura

10. Redução das Desigualdades

11. Cidades e Comunidades Sustentáveis

12. Consumo e Produção Responsáveis

14. Vida na Água

15. Vida Terrestre
Metas

1.1. Erradicar a pobreza extrema

1.2 Reduzir pelo menos à metade a proporção de pessoas na pobreza

1.4 Garantir que todos os homens e mulheres tenham direitos iguais aos recursos econômicos, serviços básicos e recursos naturais

2.3 Dobrar a produtividade agrícola e a renda dos pequenos produtores de alimentos

2.a Aumentar o investimento em infraestrutura rural

3.1 Reduzir a taxa de mortalidade materna

3.2 Acabar com as mortes evitáveis de recém-nascidos e de crianças menores de 5 anos

3.3 Combater doenças transmitidas pela água e outras doenças transmissíveis

3.9 Reduzir o número de mortes e doenças por contaminação e poluição da água

4.1 Garantir que todas as crianças completem o ensino primário e secundário

4.2 Garantir que todas as crianças tenham acesso a desenvolvimento de qualidade na primeira infância, a cuidados e a educação pré-escolar

6.1 Alcançar o acesso universal e equitativo a água potável e segura para todos

6.2 Alcançar o acesso a saneamento e higiene adequados e equitativos para todos

6.3 Melhorar a qualidade da água, reduzindo a poluição e as águas residuais não tratadas

6.4 Aumentar a eficiência do uso da água, assegurar retiradas sustentáveis e o abastecimento de água doce para enfrentar a escassez de água

6.5 Implementar a gestão integrada dos recursos hídricos em todos os níveis

6.6 Proteger e restaurar ecossistemas relacionados à água

6.a Ampliar a cooperação internacional e o apoio à capacitação para atividades e programas relacionados à água e saneamento 6.b Apoiar e fortalecer a participação das comunidades locais para melhorar a gestão da água e do saneamento 8.1 Sustentar o crescimento econômico per capita

8.2 Atingir níveis mais elevados de produtividade das economias

8.9 Elaborar e implementar políticas para promover o turismo sustentável

9.1 Desenvolver infraestrutura de qualidade, confiável, sustentável e resiliente para apoiar o desenvolvimento econômico e o bem-estar humano 10.3 Garantir a igualdade de oportunidades e reduzir as desigualdades de resultados

11.1 Garantir o acesso de todos à habitação segura e adequada e aos serviços básicos e urbanizar as favelas

11.3 Aumentar a urbanização inclusiva e sustentável

11.5 Reduzir o número de mortes e o número de pessoas afetadas por catástrofes, incluindo os desastres relacionados à água

12.2 Alcançar a gestão sustentável e o uso eficiente dos recursos naturais

14.1 Prevenir e reduzir significativamente a poluição marinha de todos os tipos, especialmente a advinda de atividades terrestres

14.c Assegurar a conservação e o uso sustentável dos oceanos e seus recursos

15.1 Assegurar a conservação, recuperação e uso sustentável de ecossistemas terrestres e de água doce interiores e seus serviços

Fonte: ONU (2015). Elaboração própria. 
Por último, vale ressaltar que ações no saneamento influenciam outras dimensões, porém, algumas delas, principalmente relativas à renda e à educação, determinam o acesso e suas desigualdades em termos regionais e associadas aos rendimentos domiciliares. Quanto maiores as rendas e os níveis educacionais, maiores as capacidades de pagamento dos consumidores pelos serviços (tarifas e gastos com as instalações), ao mesmo tempo em que eleva a consciência sobre meio ambiente e saúde, elevando a demanda por serviços adequados e a pressão sobre provedores nesse sentido (controle social). Em termos agregados, municípios passam a ter maiores capacidades de arrecadação e de investimento (GRADSTEIN; JUSTMAN, 1999).

\subsection{Simulações: possibilidades de cumprimento das metas nas mesorregiões mineiras}

Nessa subseção, é averiguado se a manutenção das taxas de queda dos déficits de acesso observadas entre 1990 e 2010 seriam suficientes para cumprir as metas dos ODSs de universalização da cobertura dao abastecimento de água e da coleta de esgoto, de forma equitativa, em Minas Gerais. Ou seja, se até 2030, a universalização do acessoseria alcançada em todo o estado, sem disparidades territoriais (mesorregiões) e entre os domicílios "mais pobres" e "mais ricos". Para isso, são usados dados censitários de 1991, 2000 e 2010 para 3 simulações, que se diferenciam em relação às taxas usadas para projetar os déficits em 2030:

- $\quad$ simulação I: taxas anuais de variações dos déficits observadas entre 1991 e 2000;

- $\quad$ simulação II: taxas anuais de variações dos déficits observadas entre 2000 e 2010;

- $\quad$ simulação III: taxas anuais de variações dos déficits observadas entre 1991 e 2010.

Para as simulações, são calculadas as taxas equivalentes anuais de variações dos déficits de acesso (total e por quintis) para cada serviço de saneamento, em cada mesorregião e em cada período. Estas taxas são utilizadas para projetar os déficits em 2030. As metas específicas dos ODSs para abastecimento de água e coleta de esgoto definem o acesso universal e equitativo. Logo, os déficits ideais para 2030 são zero. Assim, a mesorregião atingirá a meta se as variações forem suficientes para zerar os déficits em 2030.

As metas dos ODSs foram estabelecidas para pessoas. Porém, neste estudo, a unidade de análise é o domicílio, em acordo com os parâmetros de universalização da Lei do Saneamento Básico (BRASIL, 2007). Esta escolha não enviesa tanto as análises, pois o número médio de pessoas por domicílio não altera muito entre as localidades e no tempo. Ademais, nos ODSs não foram definidas as formas de acesso, optando-se por usar a mais adequada segundo a literatura: rede geral. Como já mencionado, esta é mais sustentável e com menores externalidades negativas ambientais e sobre a saúde, contribuindo, assim, para o cumprimento de parte dos ODSs e suas metas. A rede geral também é a forma mais diretamente influenciada por políticas.

A Tabela 15 mostra as simulações do cumprimento da meta 6.1, a qual visa à universalização do acesso a abastecimento de água. Observa-se que nenhuma mesorregião atingiria a meta, independente da simulação. Como as taxas de reduções dos déficits na década de 1990 foram, no geral, superiores às taxas de reduções nos anos 2000, mesmo não atingindo a meta, as mesorregiões estariam mais próximas disso se tivessem mantido as quedas dos anos 1990. Neste caso, o maior déficit em 2030 seria de 12,9\%, enquanto o menor seria de $1,3 \%$. Por outro lado, se forem mantidas as taxas de reduções de 2000 a 2010, em 2030, as mesorregiões apresentariam os maiores déficits estimados, que variam de $25,6 \%$ a 2,6\%. Considerando que as reduções da década de 2000 já representam uma ruptura da tendência dos anos 1990, a simulação II é um cenário mais provável e conservador, mesmo sendo o pior para as mesorregiões. Assim, estas precisam expandir o acesso a abastecimento de água acima do observado nos anos 1990, ou seja, devem investir para reduzir os déficits de acesso a água mais do que tem sido realizado nos últimos 20 anos para conseguirem cumprir a meta 6.1 até 2030 . Vale ressaltar que a simulação II é a mais favorável para o cumprimento da meta 6.1 no estado total, pois para este as maiores quedas dos déficits ocorreram nos anos 2000 (Tabela 5).

A Tabela 16 mostra as simulações do cumprimento da meta 6.1 dos ODSs para os "mais pobres". Estas simulações permitem avaliar se o avanço da cobertura será equitativo, exigência presente na meta. A universalização do acesso dos "mais pobres" a água não seria alcançada em nenhuma mesorregião e no estado. Pela simulação I, mesmo não alcançando a meta 6.1, se as mesorregiões e o estado mantivessem as reduções dos déficits dos anos 1990, estariam mais próximos de alcançá-la. Contudo, pela simulação II, 
cenário mais provável e conservador, se mantidas as reduções dos anos 2000, os déficits seriam quase o dobro aos da simulação I. Portanto, além de melhorar o acesso a água, investindo na redução dos déficits, também é necessário se preocupar em atender os "mais pobres" para cumprir a meta 6.1 de forma equitativa.

Tabela 15 - Minas Gerais: simulações de cumprimento da meta dos ODSs de reduções dos déficits de acesso a abastecimento de água, segundo as mesorregiões e os tipos de simulação

\begin{tabular}{|c|c|c|c|c|c|c|}
\hline \multirow[b]{2}{*}{ Mesorregião } & \multicolumn{2}{|c|}{ Simulação I } & \multicolumn{2}{|c|}{ Simulação II } & \multicolumn{2}{|c|}{ Simulação III } \\
\hline & $\begin{array}{c}\text { Déficit em } \\
2030 \\
\end{array}$ & $\begin{array}{c}\text { Cumpriria } \\
\text { a Meta? }\end{array}$ & $\begin{array}{c}\text { Déficit em } \\
2030\end{array}$ & $\begin{array}{c}\text { Cumpriria } \\
\text { a Meta? }\end{array}$ & $\begin{array}{c}\text { Déficit em } \\
2030 \\
\end{array}$ & $\begin{array}{c}\text { Cumpriria } \\
\text { a Meta? }\end{array}$ \\
\hline Campo das Vertentes & 5,9 & Não & 8,4 & Não & 7,3 & Não \\
\hline Central Mineira & 4,8 & Não & 9,6 & Não & 7,2 & Não \\
\hline Jequitinhonha & 12,9 & Não & 25,6 & Não & 19,0 & Não \\
\hline Metropolitana de Belo Horizonte & 1,3 & Não & 2,6 & Não & 1,9 & Não \\
\hline Noroeste de Minas & 8,5 & Não & 16,1 & Não & 12,2 & Não \\
\hline Norte de Minas & 6,7 & Não & 13,3 & Não & 10,0 & Não \\
\hline Oeste de Minas & 4,0 & Não & 6,3 & Não & 5,3 & Não \\
\hline Sul e Sudoeste de Minas & 8,9 & Não & 12,7 & Não & 11,0 & Não \\
\hline Triângulo Mineiro e Alto Paranaíba & 3,5 & Não & 6,4 & Não & 5,0 & Não \\
\hline Vale do Mucuri & 12,9 & Não & 20,7 & Não & 16,9 & Não \\
\hline Vale do Rio Doce & 11,6 & Não & 15,2 & Não & 13,7 & Não \\
\hline Zona da Mata & 8,5 & Não & 14,2 & Não & 11,4 & Não \\
\hline Estado de Minas Gerais & 6,8 & Não & 5,3 & Não & 6,2 & Não \\
\hline
\end{tabular}

Fonte: IBGE, Censos Demográficos de 1991, 2000 e 2010. Elaboração própria.

Tabela 16 - Minas Gerais: simulações de cumprimento da meta dos ODSs de reduções dos déficits de acesso dos "mais pobres" a abastecimento de água, segundo as mesorregiões e os tipos de simulação

\begin{tabular}{|c|c|c|c|c|c|c|}
\hline \multirow[b]{2}{*}{ Mesorregião } & \multicolumn{2}{|c|}{ Simulação I } & \multicolumn{2}{|c|}{ Simulação II } & \multicolumn{2}{|c|}{ Simulação III } \\
\hline & $\begin{array}{c}\text { Déficit em } \\
2030\end{array}$ & $\begin{array}{c}\text { Cumpriria } \\
\text { a Meta? }\end{array}$ & $\begin{array}{c}\text { Déficit em } \\
2030\end{array}$ & $\begin{array}{c}\text { Cumpriria } \\
\text { a Meta? }\end{array}$ & $\begin{array}{l}\text { Déficit em } \\
2030\end{array}$ & $\begin{array}{c}\text { Cumpriria } \\
\text { a Meta? }\end{array}$ \\
\hline Campo das Vertentes & 7,7 & Não & 11,0 & Não & 9,6 & Não \\
\hline Central Mineira & 4,6 & Não & 12,1 & Não & 8,0 & Não \\
\hline Jequitinhonha & 21,2 & Não & 40,0 & Não & 30,3 & Não \\
\hline Metropolitana de Belo Horizonte & 1,5 & Não & 3,0 & Não & 2,3 & Não \\
\hline Noroeste de Minas & 11,0 & Não & 19,1 & Não & 15,2 & Não \\
\hline Norte de Minas & 10,6 & Não & 18,7 & Não & 14,8 & Não \\
\hline Oeste de Minas & 5,7 & Não & 7,9 & Não & 7,1 & Não \\
\hline Sul e Sudoeste de Minas & 11,0 & Não & 15,8 & Não & 13,7 & Não \\
\hline Triângulo Mineiro e Alto Paranaíba & 4,6 & Não & 7,8 & Não & 6,3 & Não \\
\hline Vale do Mucuri & 22,0 & Não & 30,4 & Não & 26,6 & Não \\
\hline Vale do Rio Doce & 14,1 & Não & 18,2 & Não & 16,7 & Não \\
\hline Zona da Mata & 12,4 & Não & 19,7 & Não & 16,3 & Não \\
\hline Estado de Minas Gerais & 6,9 & Não & $\mathbf{1 1 , 8}$ & Não & 9,5 & Não \\
\hline
\end{tabular}

Fonte: IBGE, Censos Demográficos de 1991, 2000 e 2010. Elaboração própria.

A Tabela 17 apresenta as simulações para os 20\% "mais ricos". Observa-se que nem para os "mais ricos" a universalização do acesso a abastecimento de água seria alcançada nas mesorregiões mineiras e no estado. No entanto, os déficits "dos mais ricos" seriam inferiores aos déficits dos "mais pobres" nas três simulações em quase todas as mesorregiões e no total do estado, com exceção da Central Mineira na simulação I. Assim como total e $1^{\circ}$ quintil (Tabelas 15 e 16), a simulação I resulta nos menores déficits.

A Tabela 18 mostra as simulações para a meta 6.2 dos ODSs, que define a universalização do acesso a saneamento. Considera-se a coleta de esgoto. Nenhuma das mesorregiões conseguiria alcançar a meta se mantivesse quaisquer das reduções entre 1991 e 2010. As diferenças entre os déficits pelas simulações I e II para o esgoto são menores do que para água (Tabela 15), o que advém das evoluções dos acessos a esgoto terem sido mais próximos nos anos 1990 e 2000. Com exceção do Noroeste de Minas, todas as mesorregiões apresentariam menores déficits em 2030 se mantivessem as reduções dos anos 1990. Já no estado, a redução dos anos 2000. A simulação II é o cenário mais provável e conservador, pois são reduções dos anos mais recentes. Assim, são necessários "esforços" maiores aos dos anos analisados para universalizar o acesso.

A Tabela 19 apresenta as simulações para os déficits de acesso dos "mais pobres" a esgoto. Em todas as mesorregiões e no estado, não seriam atingidas a meta se forem mantidas as evoluções no período 
analisado. A simulação II, considerada mais provável e conservadora, mostra resultados preocupantes: além de não alcançarem a meta, algumas mesorregiões teriam déficits de acesso dos pobres superiores a 50\%.

Tabela 17 - Minas Gerais: simulações de cumprimento da meta dos ODSs de reduções dos déficits de acesso dos "mais ricos" a abastecimento de água, segundo as mesorregiões e os tipos de simulação

\begin{tabular}{c|c|c|c|c|cc}
\hline \multirow{2}{*}{ Mesorregião } & \multicolumn{2}{|c|}{ Simulação I } & \multicolumn{2}{|c|}{ Simulação II } & \multicolumn{2}{c}{ Simulação III } \\
\cline { 2 - 7 } & $\begin{array}{c}\text { Déficit em } \\
\mathbf{2 0 3 0}\end{array}$ & $\begin{array}{c}\text { Cumpriria } \\
\text { a Meta? }\end{array}$ & $\begin{array}{c}\text { Déficit em } \\
\mathbf{2 0 3 0}\end{array}$ & $\begin{array}{c}\text { Cumpriria } \\
\text { a Meta? }\end{array}$ & $\begin{array}{c}\text { Déficit em } \\
\mathbf{2 0 3 0}\end{array}$ & $\begin{array}{c}\text { Cumpriria } \\
\text { a Meta? }\end{array}$ \\
\hline Campo das Vertentes & 5,2 & Não & 6,2 & Não & 5,9 & Não \\
Central Mineira & 5,7 & Não & 9,1 & Não & 7,4 & Não \\
Jequitinhonha & 6,2 & Não & 24,4 & Não & 13,1 & Não \\
Metropolitana de Belo Horizonte & 1,0 & Não & 2,7 & Não & 1,7 & Não \\
Noroeste de Minas & 8,5 & Não & 16,0 & Não & 12,1 & Não \\
Norte de Minas & 4,0 & Não & 12,9 & Não & 7,7 & Não \\
Oeste de Minas & 3,0 & Não & 5,9 & Não & 4,4 & Não \\
Sul e Sudoeste de Minas & 7,8 & Não & 11,4 & Não & 9,7 & Não \\
Triângulo Mineiro e Alto Paranaíba & 3,8 & Não & 7,5 & Não & 5,6 & Não \\
Vale do Mucuri & 5,2 & Não & 19,2 & Não & 10,7 & Não \\
Vale do Rio Doce & 10,2 & Não & 12,4 & Não & 11,5 & Não \\
Zona da Mata & 6,7 & Não & 9,4 & Não & 8,2 & Não \\
\hline Estado de Minas Gerais & $\mathbf{4 , 0}$ & Não & $\mathbf{8 , 2}$ & Não & $\mathbf{6 , 0}$ & Não \\
\hline
\end{tabular}

Fonte: IBGE, Censos Demográficos de 1991, 2000 e 2010. Elaboração própria.

Tabela 18 - Minas Gerais: simulações de cumprimento da meta dos ODSs de reduções dos déficits de acesso a coleta de esgoto, segundo as mesorregiões e os tipos de simulação

\begin{tabular}{c|c|c|c|c|cc}
\hline \multirow{2}{*}{ Mesorregião } & \multicolumn{2}{|c|}{ Simulação I } & \multicolumn{2}{c|}{ Simulação II } & \multicolumn{2}{c}{ Simulação III } \\
\cline { 2 - 7 } & $\begin{array}{c}\text { Déficit em } \\
\mathbf{2 0 3 0}\end{array}$ & $\begin{array}{c}\text { Cumpriria } \\
\text { a Meta? }\end{array}$ & $\begin{array}{c}\text { Déficit em } \\
\mathbf{2 0 3 0}\end{array}$ & $\begin{array}{c}\text { Cumpriria } \\
\text { a Meta? }\end{array}$ & $\begin{array}{c}\text { Déficit em } \\
\mathbf{2 0 3 0}\end{array}$ & $\begin{array}{c}\text { Cumpriria } \\
\text { a Meta? }\end{array}$ \\
\hline Campo das Vertentes & 5,75 & Não & 9,06 & Não & 7,56 & Não \\
Central Mineira & 5,79 & Não & 8,58 & Não & 7,36 & Não \\
Jequitinhonha & 18,8 & Não & 21,22 & Não & 20,49 & Não \\
Metropolitana de Belo Horizonte & 2,17 & Não & 2,41 & Não & 2,39 & Não \\
Noroeste de Minas & 12,64 & Não & 12,5 & Não & 12,91 & Não \\
Norte de Minas & 16,51 & Não & 16,84 & Não & 16,88 & Não \\
Oeste de Minas & 3,68 & Não & 5,01 & Não & 4,54 & Não \\
Sul e Sudoeste de Minas & 7,58 & Não & 11,93 & Não & 9,93 & Não \\
Triângulo Mineiro e Alto Paranaíba & 2,62 & Não & 5,48 & Não & 4,05 & Não \\
Vale do Mucuri & 13,08 & Não & 19,19 & Não & 16,44 & Não \\
Vale do Rio Doce & 10,35 & Não & 11,44 & Não & 11,32 & Não \\
Zona da Mata & 8,62 & Não & 14,66 & Não & 11,7 & Não \\
Estado de Minas Gerais & $\mathbf{1 3 , 6}$ & Não & $\mathbf{1 0 , 5}$ & Não & $\mathbf{1 2 , 3}$ & Não \\
\hline
\end{tabular}

Fonte: IBGE, Censos Demográficos de 1991, 2000 e 2010. Elaboração própria.

Tabela 19 - Minas Gerais: simulações de cumprimento da meta dos ODSs de reduções dos déficits de acesso dos "mais pobres" a coleta de esgoto, segundo as mesorregiões e os tipos de simulação

\begin{tabular}{c|c|c|c|c|cc}
\hline \multirow{2}{*}{ Mesorregião } & \multicolumn{2}{|c|}{ Simulação I } & \multicolumn{2}{|c|}{ Simulação II } & \multicolumn{2}{c}{ Simulação III } \\
\cline { 2 - 7 } & $\begin{array}{c}\text { Déficit em } \\
\mathbf{2 0 3 0}\end{array}$ & $\begin{array}{c}\text { Cumpriria } \\
\text { a Meta? }\end{array}$ & $\begin{array}{c}\text { Déficit em } \\
\mathbf{2 0 3 0}\end{array}$ & $\begin{array}{c}\text { Cumpriria } \\
\text { a Meta? }\end{array}$ & $\begin{array}{c}\text { Déficit em } \\
\mathbf{2 0 3 0}\end{array}$ & $\begin{array}{c}\text { Cumpriria } \\
\text { a Meta? }\end{array}$ \\
\hline Campo das Vertentes & 11,7 & Não & 20,1 & Não & 16,2 & Não \\
Central Mineira & 20,4 & Não & 25,0 & Não & 23,4 & Não \\
Jequitinhonha & 47,2 & Não & 50,1 & Não & 49,5 & Não \\
Metropolitana de Belo Horizonte & 8,7 & Não & 9,5 & Não & 9,5 & Não \\
Noroeste de Minas & 32,4 & Não & 30,8 & Não & 32,4 & Não \\
Norte de Minas & 57,3 & Não & 59,6 & Não & 59,2 & Não \\
Oeste de Minas & 8,6 & Não & 9,7 & Não & 9,6 & Não \\
Sul e Sudoeste de Minas & 10,7 & Não & 16,4 & Não & 13,9 & Não \\
Triângulo Mineiro e Alto Paranaíba & 4,5 & Não & 9,3 & Não & 7,0 & Não \\
Vale do Mucuri & 30,8 & Não & 39,7 & Não & 36,0 & Não \\
Vale do Rio Doce & 15,6 & Não & 16,8 & Não & 16,8 & Não \\
Zona da Mata & 14,8 & Não & 24,9 & Não & 20,0 & Não \\
\hline Estado de Minas Gerais & $\mathbf{1 4 , 0}$ & Não & $\mathbf{1 8 , 4}$ & Não & $\mathbf{1 6 , 8}$ & Não \\
\hline
\end{tabular}

Fonte: IBGE, Censos Demográficos de 1991, 2000 e 2010. Elaboração própria. 
A Tabela 20 mostra as simulações do cumprimento da meta de universalização do acesso a coleta de esgoto, até 2030, para os domicílios "mais ricos”. De modo geral, a simulação I é o cenário mais favorável, no qual as mesorregiões e o estado atingiriam os menores déficits. Na II, mais provável e conservadora, os déficits seriam maiores em relação à $I$ em todas as mesorregiões e no estado, com exceção da mesorregião Norte de Minas. Observa-se, ainda, que apesar de não atingir a universalização, os déficits "dos mais ricos" seriam inferiores aos déficits dos "mais pobres" nas três simulações, em todas as mesorregiões e no estado.

Tabela 20 - Minas Gerais: simulações de cumprimento da meta dos ODSs de reduções dos déficits de acesso dos "mais ricos" a coleta de esgoto, segundo as mesorregiões e os tipos de simulação

\begin{tabular}{|c|c|c|c|c|c|c|}
\hline \multirow[b]{2}{*}{ Mesorregião } & \multicolumn{2}{|c|}{ Simulação I } & \multicolumn{2}{|c|}{ Simulação II } & \multicolumn{2}{|c|}{ Simulação III } \\
\hline & $\begin{array}{l}\text { Déficit em } \\
2030\end{array}$ & $\begin{array}{c}\text { Cumpriria } \\
\text { a Meta? }\end{array}$ & $\begin{array}{c}\text { Déficit em } \\
2030\end{array}$ & $\begin{array}{c}\text { Cumpriria } \\
\text { a Meta? }\end{array}$ & $\begin{array}{c}\text { Déficit em } \\
2030\end{array}$ & $\begin{array}{c}\text { Cumpriria } \\
\text { a Meta? }\end{array}$ \\
\hline Campo das Vertentes & 6,9 & Não & 12,9 & Não & 9,8 & Não \\
\hline Central Mineira & 10,9 & Não & 18,6 & Não & 14,8 & Não \\
\hline Jequitinhonha & 19,5 & Não & 29,2 & Não & 24,7 & Não \\
\hline Metropolitana de Belo Horizonte & 5,7 & Não & 7,0 & Não & 6,5 & Não \\
\hline Noroeste de Minas & 21,1 & Não & 22,1 & Não & 22,1 & Não \\
\hline Norte de Minas & 48,2 & Não & 45,3 & Não & 47,2 & Não \\
\hline Oeste de Minas & 4,0 & Não & 6,6 & Não & 5,4 & Não \\
\hline Sul e Sudoeste de Minas & 7,7 & Não & 12,7 & Não & 10,2 & Não \\
\hline Triângulo Mineiro e Alto Paranaíba & 3,9 & Não & 8,3 & Não & 6,0 & Não \\
\hline Vale do Mucuri & 10,1 & Não & 20,6 & Não & 15,1 & Não \\
\hline Vale do Rio Doce & 10,2 & Não & 12,0 & Não & 11,4 & Não \\
\hline Zona da Mata & 9,1 & Não & 13,9 & Não & 11,6 & Não \\
\hline Estado de Minas Gerais & 9,6 & Não & 13,5 & Não & $\mathbf{1 1 , 8}$ & Não \\
\hline
\end{tabular}

Fonte: IBGE, Censos Demográficos de 1991, 2000 e 2010. Elaboração própria.

\section{Considerações finais}

Para elevar a produtividade industrial, é fundamental a provisão adequada de serviços de saneamento, pois estes podem impactar fortemente as atividades industriais. Devido à água ser um importante insumo de produção para vários setores industriais, quantidades insuficientes de água para a produção prejudicam a produtividade total dos fatores das empresas industriais. Ademais, quantidades insuficientes de água para o consumo humano, água contaminada e problemas associados aos outros serviços de saneamento afetam, via saúde, a produtividade dos trabalhadores. O grande problema é que o Brasil apresenta sérios déficits de acesso a formas adequadas de abastecimento de água e, principalmente, de coleta de esgoto, distribuídos desigualmente no território. Tal problema é observado também dentro de estados, como em Minas Gerais.

Este estudo mostrou, para 2010, que há disparidades entre as mesorregiões mineiras quanto ao acesso a abastecimento de água e a coleta de esgoto, mas que todas são, em algum grau, deficitárias. As análises também sinalizaram: i) piores situações das coberturas da coleta de esgoto em todas as mesorregiões; ii) mesorregiões com maiores déficits de acesso possuem menores taxas de urbanização e menores níveis de renda - em acordo com a literatura sobre determinantes do acesso a saneamento - e se localizam mais ao norte do estado, área tradicionalmente menos desenvolvida; e iii) a cobertura dos domicílios "mais ricos" é maior que a dos "mais pobres", nos dois serviços e em todas as mesorregiões mineiras.

Além disso, com análises das evoluções de 1991 a 2010, observou-se reduções dos déficits de acesso nos dois serviços em todas as regiões, mais acentuadas nos anos 1990, o que sugere que o melhor quadro institucional e a maior alocação de recursos no final dos anos 2000, no mínimo, não foram suficientes para gerarem retornos imediatos em termos de avanço do acesso. As análises evidenciaram, ainda, convergências entre os acessos a saneamento das mesorregiões mineiras e dos domicílios "mais pobres" e "mais ricos".

Adicionalmente, foram realizadas simulações para verificar se a manutenção das reduções dos déficits ocorridas entre 1990 e 2010 seriam suficientes para o alcance das metas específicas dos ODSs de universalização equitativa, até 2030, do acesso a abastecimento de água e coleta de esgoto no estado de Minas Gerais. Ou seja, se a universalização do acesso seria alcançada em todo o estado, sem disparidades territoriais (mesorregiões) e associadas à renda (domicílios "mais pobres" e "mais ricos"). Tais simulações evidenciaram que as mesorregiões mineiras e o total do estado não atingirão a meta de universalização dos 
serviços de saneamentos se não realizarem investimentos superiores aos feitos nas décadas de 1990 e 2000. Este fato se torna mais grave frente a "perda de força" das quedas dos déficits nos anos 2000.

Vale ressaltar, ainda, o fato dos déficits de acesso a saneamento em Minas Gerais se reduzirem em ritmo não suficientes para a universalização, mas diminuindo as desigualdades de acesso associadas à renda. As expansões dos acessos dos "mais pobres" foram, no geral, superiores aos dos "mais ricos". Assim, não é possível afirmar que os "mais pobres" estão "ficando para trás" com o avanço das coberturas dos serviços de saneamento. Porém, o mesmo não pode ser dito sobre as mesorregiões, em especial do norte do estado.

\section{Referências bibliográficas}

ANA. Água na indústria: uso e coeficientes técnicos. ANA, 2017.

ANA. Atlas Brasil: abastecimento urbano de água. ANA, 2010.

ASCHAUER, D. "Is public expenditure productive?" Journal of Monetary Economics, v.23, n.2, 1989.

BARAT, J. O financiamento da infraestrutura urbana: os impasses, as perspectivas institucionais, as perspectivas financeiras. IPEA, 1998.

BNDES. Saneamento: o objetivo é a eficiência. Informes Infra-Estrutura, n.23, BNDES, jun., 1998.

BRASIL. Lei Federal $n^{o} 11.445$, janeiro de 2007. Lei Nacional de Saneamento Básico.

BREGMAN, A.; MAROM, A. Productivity factors in Israel's manufacturing industry. Bank of Israel Economic Review, n.72, 1999.

CAIRNCROSS, S. Aspectos de saúde nos sistemas de saneamento básico. Engenharia Sanitária, 1984.

COSTA, C. C. de M.; FERREIRA, M. A. M.; BRAGA, M. J.; ABRANTES, L. A. Disparidades interregionais e características dos municípios do estado de Minas Gerais. Desenvolvimento em Questão, Editora Unijuí, ano 10, n. 20, maio/ago. 2012.

CVJETANOVIC, B. Health effects and impact of water supply and sanitation. World Health Statistics Quarterly, v. 39, p. 105-117, 1986.

DE NEGRI, F.; CAVALCANTE, L. R. Produtividade no Brasil: desempenho e determinantes desempenho, v.1., IPEA, Brasília, 2014.

GRADSTEIN, M.; JUSTMAN, M. The democratization of political elites and the decline inequality in modern economic growth. In: BREZIS, E.; TEMIN, P. (eds.). Elites, Minorities and Economic Growth, Elsevier, Amsterdam, 1999.

HELLER, L. Saneamento e saúde. Brasília: Organização Pan-Americana da Saúde, 1997.

IBGE. Atlas de Saneamento 2011. IBGE, Rio de Janeiro, 2011.

IPEA. Infraestrutura econômica no Brasil: diagnósticos e perspectivas para 2025. IPEA, 2010.

JMP. Wasf in the 2030 Agenda: new global indicators for drinking water, sanitation and hygiene. Joint Monitoring Programme for Water Supply, WHO, Unicef, 2017.

LEIPZIGER, D.; FAY, M.; WODON, Q.; YEPES, T. Achieving the Millennium Development Goals: the role of infrastructure. World Bank Policy Research Working Paper, n. 3163, nov. 2003.

MADEIRA, R. F. O setor de saneamento básico no Brasil e as implicações do marco regulatório para universalização do acesso. Revista do BNDES, Rio de Janeiro, n. 33, p. 123-154, jun. 2010.

MASTROMARCO, C.; WOITEK, W. "Public infrastructure investment and efficiency in Italian regions". Journal of Productivity Analysis, v. 25, n.1-2, 2006.

MPO; IPEA. Diagnóstico do setor de saneamento: estudo econômico e financeiro. Série Modernização do Setor Saneamento, n. 7, MPO, IPEA, Brasília, 1995.

MOTTA, R. S. Questões regulatórias do setor de saneamento no Brasil. Notas Técnicas do IPEA, 2004.

MOYO, B. "Do water cuts affect productivity? Case study of African manufacturing firms". Water SA, v.37, n.3, 2011.

MUSSOLINI, C.; TELES, V. K. "Infraestrutura e produtividade no Brasil”. Revista de Economia Política, v.30, n.4, 2010.

NUSSBAUM, M. C. Creating capabilities: the human development approach. Harvard University, 2011.

ONU. Transformando nosso mundo: a agenda 2030 para o desenvolvimento sustentável. Organizações das Nações Unidas, 2015. 
PNUD. Relatório do Desenvolvimento Humano 2006. New York: Programa das Nações Unidas para o Desenvolvimento, 2006.

QUEIROZ. B. L. Diferencial regional de salários e retornos sociais à educação: uma abordagem hierárquica. In: WAJNMAN, S.; MACHADO, A. F. (Org.). Mercado de trabalho: uma análise a partir das pesquisas domiciliares no Brasil. Belo Horizonte: UFMG, 2003.

REZENDE, S. C; WAJNMAN, S.; CARVALHO, J. A. M.; HELLER, L. Integrando oferta e demanda de serviços de saneamento: análise hierárquica do panorama urbano brasileiro no ano 2000. Engenharia Sanitária Ambiental, Rio de Janeiro, v. 12, n. 1, jan./mar., 2007.

RIGOLON, F. J. Z. "O investimento em infraestrutura e a retomada do crescimento econômico sustentado". Pesquisa e Planejamento Econômico, v.28, n. 1, 1998.

ROMEIRO, A. R. Economia ou Economia Política da Sustentabilidade. In MAY, P.; LUSTOSA, M. C.; VINHA, V. Economia do Meio Ambiente. Campus, Rio de Janeiro 2003.

SAIANI, C. C. S. Déficit de acesso aos serviços de saneamento básico no Brasil. In: IPEA; CAIXA. Prêmio IPEA-CAIXA de Monografias. Instituto de Pesquisa Econômica Aplicada, Caixa Econômica Federal, 2006. SAIANI, C. C. S.; TONETO JÚNIOR, R. Evolução do acesso a serviços de saneamento básico no Brasil (1970 a 2004). Economia e Sociedade, Campinas, v. 19, n. 38, abr. 2010.

SAIANI, C. C. S.; TONETO JÚNIOR, R.; DOURADO, J. Déficit de acesso a serviços de saneamento ambiental: evidências de uma Curva Ambiental de Kuznets para o caso dos municípios brasileiros? Economia e Sociedade, Campinas, v. 22, 2013a.

SAIANI, C. C. S.; TONETO JÚNIOR, R.; DOURADO, J. Desigualdade de acesso a serviços de saneamento ambiental nos municípios brasileiros: evidências de uma Curva de Kuznets e de uma Seletividade Hierárquica das Políticas? Nova Economia, v. 23, 2013 b.

SAIANI, C. C. S.; RODRIGUES, R. L.; GALVÃO, G. C. Saneamento básico no Brasil e Objetivos de Desenvolvimento do Milênio: evoluções dos déficits de acesso de 1990 a 2010. Cadernos de Ciências Sociais Aplicadas, UESB, v. 12, p. 329-360, 2015.

SALVATO, M. A.; RAAD, R. J.; ARAUJO JUNIOR, A. F.; PESSOA, F. M. Disparidades regionais em Minas Gerais. Anais do XII Seminário sobre a Economia Mineira, Diamantina, 2006.

SAMPAIO, B; SAMPAIO, Y. Influências políticas na eficiência de empresas de saneamento brasileiras. Economia Aplicada, v. 11, n. 3, jul.-set., 2007.

SCHETTINI, D.; AZZONI, C. "Determinantes regionais da produtividade industrial: o papel da infraestrutura". In: DE NEGRI, F.; CAVALCANTE, L. R. Produtividade no Brasil: desempenho e determinantes - desempenho, v.1, IPEA, 2014.

SEN, A. K. Capacidad y bienestar. In: NUSSBAUM, M. C.; SEN, A. (orgs) La calidad de vida. Fondo de Cultura Económica, Mexico, 1996.

SEN, A. K. Desenvolvimento como liberdade. Companhia das Letras, São Paulo, 2000.

SEN, A. K. Desigualdade reexaminada. Record, Rio de Janeiro, 2001.

SIMÃO, R. C. S. A contribuição das parcelas do rendimento que formam a renda domiciliar per capita para a desigualdade em Minas Gerais de acordo com os dados do Censo Demográfico 2000. Anais do XII Seminário sobre a Economia Mineira, Diamantina, 2006.

SNSA. Panorama do saneamento básico no Brasil. Ministério das Cidades, Brasília, 2011.

SOARES, W. R. "Diferenças salariais e desigualdades de renda nas mesorregiões mineiras: uma análise a partir dos microdados da RAIS utilizando regressão quantílica”. Revista Econômica do Nordeste, 2009.

TONETO JÚNIOR, R.; SAIANI, C. C. S. Restrições à Expansão dos Investimentos no Saneamento Básico Brasileiro. Revista Econômica do Nordeste, v. 37, p. 572-591, 2006.

TUROLLA, F. A. Política de saneamento básico: avanços recentes e opções futuras de políticas públicas. Textos para Discussão do IPEA, Brasília, n. 922, dez. 2002.

UCHIMURA, K.; GAO, H. The importance of infrastructure on economic development. World Bank, Latin America and the Caribbean Regional Office, Washington, 1993.

VICTORA, C. G.; GRASSI, P. R.; SCHMIDT, A. M. Situação de saúde da criança em área da região sul do Brasil, 1980-1992: tendências temporais e distribuição espacial”. Revista de Saúde Pública, 1994. 